\author{
Universidade de São Paulo \\ Faculdade de Filosofia, Letras e Ciências Humanas \\ Departamento de Ciência Política
}

Rafael Nunes Magalhães

Os Determinantes da Ajuda Externa Brasileira

São Paulo

2013 
Universidade de São Paulo

Faculdade de Filosofia, Letras e Ciências Humanas

Departamento de Ciência Política

\section{Os Determinantes da Ajuda Externa Brasileira}

\section{Rafael Nunes Magalhães}

Dissertação apresentada ao Programa de Pós-

Graduação em Ciência Política da Faculdade de

Filosofia, Letras e Ciências Humanas da Uni-

versidade de São Paulo, como requisito para a

obtenção do título de Mestre em Ciência Política

Orientadora: Profa. Dra. Janina Onuki

São Paulo 
Dedico este trabalho à minha mãe 


\section{Resumo}

Este trabalho tem como objetivos analisar os acordos ajuda externa assinados pelo Brasil entre 2005 e 2010 e estudá-los à luz das diretrizes diplomáticas brasileiras no período, identificando suas determinantes conjunturais e estruturais. Em oposição às modalidades tradicionais de cooperação internacional, que são acordadas entre países com diferentes níveis de desenvolvimento econômico e diferentes interesses estratégicos, a cooperação Sul-Sul se caracteriza por envolver países em desenvolvimento, com maior potencial de identificação mútua e de convergência de interesses. Não surpreende, portanto, que essa modalidade tenha ganhado força ultimamente, na medida em que países emergentes alcançam projeção internacional e se encontram em condições mais favoráveis para fortalecer laços diplomáticos, promover o desenvolvimento econômico de parceiros comerciais (efetivos ou potenciais) e aumentar, quantitativa e qualitativamente, sua influência no âmbito internacional. No Brasil, o órgão responsável pela articulação dos acordos de cooperação internacional é a Agência Brasileira de Cooperação, vinculado ao Ministério das Relações Exteriores. Sua criação, em 1987, acompanhou o processo de abertura democrática do país e sua atuação já atravessa sete mandatos presidenciais tão variados em suas orientações políticas quanto nos contextos externos que eles enfrentaram. A compreensão de sua relevância estratégica na política externa 
brasileira não acompanhou, entretanto, a atenção que a Agência Brasileira de Cooperação tem ganhado por parte do governo federal. Este trabalho pretende analisar, a partir de um conjunto de dados coletados junto à Agência Brasileira de Cooperação, a política externa brasileira e a relevância estratégica que os projetos de cooperação Sul-Sul ganharam nos últimos governos. 


\section{Abstract}

This dissertation has two main objectives: analyze the aid donation agreements signed by Brazil between 2005 and 2010 and study their relation to the main ideas informing Brazilian diplomatic relations in the period. As opposed to traditional models of international cooperation, which are agreed between countries with different economic capacities and different strategic interests, South-South cooperation distinguishes itself by involving only underdeveloped countries, which have greater potential of mutual identification and of converging interests. Thus it does not come as a surprise that this practice has been increasingly gaining importance lately, as emergent countries have been experiencing greater international projection and meeting more favorable conditions to strengthen diplomatic ties, to promote trade partners' (effective or potential) economic development and to increase, quantitatively and qualitatively, their influence on the international realm. In Brazil, the bureaucratic body responsible for the articulation of cooperation agreements is the Brazilian Cooperation Agency, under the Ministry of Foreign Relations. Its creation in 1987 followed the Brazilian democratization process, and within its lifetime it has gone under the command of seven presidential administrations as diverse on their political orientations as on the international challenges they had to face. However, the comprehension of the Brazilian Cooperation Agency's strategic 
role in Brazil's foreign policy did not follow the increasing relevance attributed to it by the federal government in recent years. This paper intends to study Brazilian foreign policy and the strategic relevance of South-South cooperation in the last presidential administrations, based on data collected at the Brazilian Cooperation Agency. 


\section{Sumário}

1 Introdução 9

2 Ajuda Externa: Motivação, Efeitos e Novos Doadores 11

2.1 O Impacto Econômico da Ajuda Externa . . . . . . . . . . . . . . . 12

2.2 Interesses dos Doadores . . . . . . . . . . . . . . 26

2.3 Doadores Emergentes . . . . . . . . . . . . . . . 28

3 A Cooperação Brasileira 34

3.1 Conflito e Cooperação em Projetos de Desenvolvimento Interna-

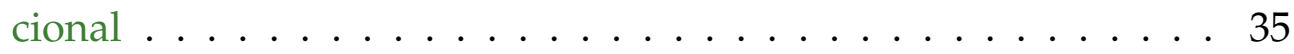

3.2 As Iniciativas Brasileiras . . . . . . . . . . . . . . . . . . 42

3.3 A Agência Brasileira de Cooperação . . . . . . . . . . . . . . . . . 48

4 A Ajuda Externa Brasileira 2005-2010 58

4.1 Tipos de Projetos . . . . . . . . . . . . . . . 63

4.2 Organização burocrática . . . . . . . . . . . . . . 66

5 Conclusão 


\section{Introdução}

Conflito e cooperação formam dois dos grandes temas em torno dos quais se organizam as Relações Internacionais, quer entendamos o termo como arena de ação política substantiva por parte dos atores internacionais, quer o entendamos como disciplina acadêmica. Historicamente, os conflitos internacionais têm sido o objeto privilegiado de atenção dos estudiosos (Keohane, 1984), particularmente entre aqueles que se inscrevem na perspectiva realista, que se estabeleceu como a orientação dominante da disciplina durante boa parte do século XX. O tema da cooperação (e, particularmente, no escopo deste trabalho, a cooperação para o desenvolvimento), entretanto, tem ganhado força nos últimos anos e tem estimulado a expansão de uma agenda de pesquisa já bastante consolidada.

As discussões centrais sobre cooperação encontram base na década de 1970, em autores que sintetizam o debate entre neorrealistas e neoinstitucionalistas que tomam a cooperação como instrumento para aumentar seus ganhos individuais. As linhas teóricas tradicionais não identificam os eventuais incentivos dos países menos desenvolvidos em promover a cooperação, tampouco iluminam a forma como se dá a interação desses interesses com a) os interesses dos países mais desenvolvidos, ou mesmo com b) os interesses dos demais 
países não-desenvolvidos. Neste sentido, uma linha de análise baseada na escolha racional tem chamado a atenção para a importância de se identificar os padrões de incentivos que se oferecem aos atores internacionais para adotar uma postura menos conflituosa em suas interações.

Boa parte da literatura sobre ajuda externa envolve também a questão sobre os interesses dos doadores em tomar parte desses projetos. Este trabalho tem o objetivo de investigar os principais determinantes da alocação de ajuda externa brasileira a partir dos anos 2000, a partir de uma base de dados de todos os projetos de cooperação empreendidos pelo país no período. A essa base, são agregadas co-variáveis que representam os interesses econômicos, políticos e humanitários do país. Os resultados encontrados contrariam a ideia de que o Brasil é um doador desinteressado, cujos projetos objetivam primordialmente as necessidade dos países recipiendários. Comércio e aproximação cultural também fazem parte da escolha de onde o Brasil decide alocar seus projetos de cooperação. Não encontramos, porém, associação entre a ajuda internacional brasileira e o aumento de sua influência política nas votações da Assembleia Geral da ONU. 


\section{Ajuda Externa: Motivação, Efeitos e Novos Doa- dores}

Por que países doam ajuda externa? Se todos os países, mesmo entre os mais desenvolvidos, podem aplicar recursos excedentes na melhoria de políticas públicas internas, o que os motiva a direcionar recursos a outros Estados? Essas perguntas forneceram a motivação para que cientistas políticos, historiadores e economistas se debrussacem sobre a razão pela a Ajuda Externa emerge com razoável proeminência a partir da segunda metade do século XX. Este capítulo procurará resumir esse debate, acentuando a importância dada pelos pesquisadores à dimensão doméstica da ajuda externa, por mais contraintuitiva que a ideia pareça.

Uma vez constatadada a existência da ajuda, quais são seus efeitos sobre os países recipiendários? Assumindo que os recursos aplicados em doações externas são parte de um fundo escasso, a permanência dessa política só seria justificada pela existência de resultados concretos, de preferência mensuráveis. Um segundo debate nas ciências sociais dá conta dessa questão, mas, como veremos adiante, os achados são inconclusivos. 


\subsection{O Impacto Econômico da Ajuda Externa}

Existem três grandes escolas de pensamento sobre a eficácia da ajuda Jensen (2012): ajuda tem uma relação positiva com o crescimento econômico, a ajuda não tem nenhum efeito sobre o crescimento econômico, e pode de fato ser prejudicial para o desenvolvimento, e ajuda tem uma relação condicional com o crescimento econômico, acelerando o crescimento em determinadas condições.

Essas linhas de achados empíricos se organizam temporalmente, de modo que, nos anos 1990, uma geração de pesquisadores filiados principalmente a programas de Economia encontram resultados nulos da ajuda sobre o crescimento econômico. (Kono and Montinola, 2009) argumentam que a ajuda externa aumenta ó consumo de bens públicos não-produtivos. (Milner and Tingley, 2010) e (Mesquita and Smith, 2009), por sua vez, identifica um efeito negativo da ajuda externa sobre a poupança da populaçao, diminuindo assim o estoque de capita disponível para investimentos. Boone(1996) argumenta que ajuda não tem impacto sobre o desenvolvimento de países recipiendário principalmente por dois motivos: primeiro, a pobreza de grande parte dos países não é causada por falta de capital, senão por sua má distribuição. Segundo, políticos que recebem os recursos externos não têm incentivos para distribuí-los de maneira equânime. Pedersen (1996), por fim, aponta que países recipiendários 
aumentam a dependência de recursos externos, em vez de se desenvolverem. Vê-se, assim, que a primeira onda da literatura empírica sobre os impactos da ajuda externa sobre as economias dos países recipiendários encaram o fenômeno como neutro, quando não pernicioso.

A partir dos anos 2000, economistas e cientistas políticos passam a encontrar resultados mais favoráveis. escrevem o artigo seminal dessa nova geração, argumentando que a doação de recursos pode ser efetiva, condicionada à existência de boas políticas internas. Introduz-se, assim, um paradoxo fundamental desse debate: os países que mais precisam de ajuda externa são aqueles que menos podem se beneficiar dela, por terem instituições menos desenvolvidas. Países de renda baixa, mas com algum grau de organização interna, são os alvos mais eficientes desse tipo de ação.

Nesse rastro, (Bräutigam, 2012) concluem que a efetividade da ajuda depende de choqus externos negativos de demanda, mais do que boas instituições. (Mesquita and Smith, 2007) prosseguem nessa linha ao afirmar que o efeito da ajuda externa sobre a pobreza depende fundamentalmente do crescimento da renda per-capita no país recipiendário. (Beck and Katz, 1995) concordam com a possibilidade de que a ajuda externa cause efeitos positivos de curto prazo, mas que no longo prazo o choque de recursos é absorvido na economia sem gerar efeitos duradouros. (?), por sua vez, encontra uma relação 
direta entre fluxos de ajuda externa e desenvolvimento econômico.

As discussões centrais sobre cooperação encontram base na década de 1970, em autores que sintetizam o debate entre neorrealistas e neoliberais, particularmente em sua vertente institucionalista. Em comum, esses autores tomam a cooperação como instrumento para aumentar seus ganhos individuais. Em diversos pontos, entretanto, pesquisadores alinhados às duas perspectivas apresentam divergências siginificativas. David Baldwin (1993, p. 4) organiza o debate conhecido como (Knack, 2004) neo-neo em seis pontos focais, quais sejam: a importância da anarquia, a possibilidade de cooperação internacional, a preponderância de ganhos relativos ou ganhos absolutos, a prioridade dos objetivos dos Estados, as tensões entre intenção e capacidade e o papel de instituições e regimes internacionais. Observemos brevemente como neorrealistas e neoinstitucionalistas se posicionam nos temas mais relevantes para os fins deste trabalho.

A constatação da ausência de uma autoridade central legítima de caráter global é cara aos neorrealistas (e ao realismo clássico) por ser uma das características basilares que distinguem a política internacional da política doméstica. Apesar de não desafiarem a existência dessa anarquia, os institucionalistas neoliberais tendem a considerá-la apenas mais um entre diversos fatores a serem analisados, inclusive aqueles que promovem os canais de cooperação e inter- 
dependência. Em uma exaustiva análise do conceito de anarquia e de seu uso nas teorias de relações internacionais, Helen Milner conclui: “while anarchy is na importante condition of world politics, it is not the only one" (1993, p. 167).

Os debates relativos à possibilidade de cooperação internacional e à importância de ganhos relativos e ganhos absolutos, por sua vez, podem ser considerados conjuntamente: neoliberais institucionalistas acreditam que Estados se orientam por ganhos absolutos, de modo que fica favorecida a possibilidade de cooperação em instituições internacionais que promova ganhos mútuos para os participantes. Neorrealistas, por sua vez, defendem que Estados dão ênfase a ganhos relativos, estando dispostos a deixar de obter mais vantagens na medida em que possam interferir nas vantagens obtidas pelos demais.

As linhas teóricas tradicionais não identificam os eventuais incentivos dos países menos desenvolvidos em promover a cooperação, tampouco iluminam a forma como se dá a interação desses interesses com a) os interesses dos países mais desenvolvidos, ou mesmo com b) os interesses dos demais países nãodesenvolvidos. Assim, uma linha de análise baseada na escolha racional tem chamado a atenção para a importância de se identificar os padrões de incentivos que se oferecem aos atores internacionais para adotar uma postura menos conflituosa em suas interações. 
Deve-se reconhecer, neste sentido, a original contribuição do livro "The Evolution of Cooperation", de Robert Axelrod (1984). Por meio de uma série de reproduções reiteradas do Dilema do Prisioneiro, Axelrod buscou responder a "uma simples pergunta: quando deve uma pessoa cooperar e quando uma pessoa deve ser egoísta em uma interação contínua com uma outra pessoa" (p. 7)?

O problema, de alcance sociológico amplo, provou ser proveitosamente aplicável nas interações entre os atores das Relações Internacionais, particularmente entre Estados que se relacionam sem a presença de uma entidade hierarquicamente superior capaz de arbitrar entre seus diferentes interesses. A resposta encontrada pelo autor à pergunta original é admiravelmente simples: a estratégia mais efetiva em uma interação contínua entre dois atores é cooperar na primeira oportunidade e, nas interações seguintes, reproduzir a ação anterior do outro ator. A essa estratégia de cooperação caracterizada pela reciprocidade deu-se o nome de TIT FOR TAT. Pode-se, como argumenta o autor, atribuir a ela a emergência de cooperação nos contextos em que esta seria a estratégia menos esperada, como a "cooperação entre antagonistas observada nas guerras de trincheiras da Primeira Guerra Mundial"' (p. 87). A cooperação, ressalta o autor, não requer amizade, senão a existência de objetivos comuns.

O Dilema do Prisioneiro é, provavelmente, a metáfora mais conhecida 
para modelar decisão estratégica (Osborne, 2004). O modelo descreve situações nas quais a cooperação entre os atores promove os ganhos mais compensadores, porém a estrutura de incentivos para cada um deles favorece o comportamento egoísta. Sem ter confiança de que o outro ator irá cooperar, o equilíbrio gera resultados sub-ótimos.

Uma extensão desse modelo é o Dilema do Prisioneiro Iterado (DPI). Neste modelo, os jogadores têm a oportunidade de jogar o Dilema do Prisioneiro diversas vezes, com a capacidade de emitir sinalização sobre sua disposição de cooperar e gerar resultados mais favoráveis. Os problemas enfrentados pela Teoria dos Jogos em ciências sociais são frequentemente desse tipo, sendo mais raras as ocasiões nas quais atores só têm a oportunidade de jogar uma vez. Corridas armamentistas, ajuste de preços em oligopólios e coalizões partidárias são exemplos em que o Dilema do Prisioneiro é jogado repetidas vezes.

Em DPI's, há oportunidade de punir desertores e premiar ações cooperativas, de modo que o equilíbrio do jogo é mais elusivo do que o Dilema do Prisioneiro em uma rodada. Axelrod (2006) promoveu um torneio de computadores para definir a estratégia mais eficiente, na qual algoritmos programados por cientistas se enfrentavam em DPI's centenas de vezes. O resultado surpreende por se originar do algoritmo mais simples: o TIT FOR TAT (TFT). Trata-se de uma estratégia de reciprocidade, na qual o jogador sempre coopera na pri- 
meira rodada e, nas rodadas seguintes, repete o comportamento do outro ator. O resultado é tão robusto que Robert Axelrod repetiu o experimento anos depois, de modo que os participantes já sabiam a estratégia vencedora anteriormente, e ainda assim TFT foi o vencedor por margem confortável. Ainda assim, é bom notar que o jogo não tem solução matematicamente rigorosa, e os motivos da vitória do TFT não são plenamente compreendidos.

Nesta mesma linha, Keohane e Axelrod (1985) sublinham que cooperação não implica harmonia completa, tampouco é necessariamente boa quando analisada de um ponto de vista moral. Os autores identificam duas arenas principais nas quais se aplicam as estratégias de cooperação e conflito nas relações internacionais: a) aquela na qual se discutem questões militares e de segurança e b) aquela na qual se discutem questões políticas e econômicas ( p. 232). Apesar de possuírem dinâmicas de interação diferentes, os autores defendem que é possível identificar uma estrutura de incentivos comum a ambas, organizando os padrões de cooperação e conflito na esfera internacional em conjunção com uma série de fatores conjunturais que se acomodam, de diferentes maneiras, no quadro mais amplo das estruturas de interação. Vê-se assim que a inexistência de um governo global comum não significaria a inexistência de uma sociedade internacional, ainda que fragmentada pela existência de variados contextos. 
As três dimensões estruturais da cooperação identificadas por Keohane e Axelrod são: a) a mutualidade de preferências, estabelecendo que quanto maior o conflito de interesses entre dois atores, maior é a possibilidade de eles não cooperarem; b) a "sombra do futuro", ou seja, a expectativa da reiteração das relações entre países, que constituiria um incentivo à cooperação por meio da combinação entre perspectiva de longo prazo e a crescente transparência de dados que informam as decisões estratégicas; e c) o número de atores envolvidos, estabelecendo que, quanto maior o número de atores simultâneos no jogo, mais difícil é identificar atores não-cooperativos e, por consequência, puni-los, diminuindo a chance de a cooperação produzir resultados positivos (p. 227). O paradigma teórico oferecido por Keohane e Axelrod fornece uma linha de investigação promissora para compreender a evolução das políticas de cooperação internacional promovidas por países não desenvolvidos, na medida em que reconhece em todos os atores, e não apenas naqueles em posição de domínio, a existência de incentivos para empreender ações em conjunto.

Estabelecidas as condições sob as quais diferentes países cooperam, fazse necessário analisar os mecanismos que impulsionam suas ações. No que diz respeito ao enquadramento dos fatores que motivam as ações dos países no âmbito externo, os trabalhos desenvolvidos com foco na formulação da política externa se posicionam de modo a sublinhar a importância dos conflitos políti- 
cos domésticos na formulação de escolhas e no processo de tomada de decisão. Contrapõe-se, assim, ao arcabouço teórico que se desenvolveu na primeira metade do século XX, particularmente pelos teóricos realistas, que se baseava na relação entre Estados unitários, estes tomados como atores coerentes agindo racionalmente com o fim satisfazer o "interesse nacional".

Graham Allison e Philip Zelikov defendem, em "Essence of Decision" (1999), a importância de se levar em consideração os estímulos e interesses organizacionais envolvidos em uma decisão com impacto externo - no caso dos autores, a reação americana ao episódio dos mísseis em Cuba. Os autores desenvolvem três modelos, cada um com bases conceituais próprias, a partir dos quais uma série de proposições são deduzidas e comparadas com os registros históricos. Deste modo, o Modelo I, de governo unitário, se concentra nos objetivos do Estado, nas estruturas de custos e ganhos potenciais na tomada de decisão e na percepção, com base nessas informações, da melhor estratégia a ser adotada.

O Modelo II, por sua vez, toma como atores principais as burocracias envolvidas na formulação da política. Segundo os autores, "in Model II explanations, the subjects are never named individuals or entire governments. Rather, the subjects of Model II are organizations, and their behavior is explained in terms of organizational purposes and practices common to the members of the 
organization, not those particular to one or another individual"' (p. 145). Assim, as deduções originadas do Modelo II se baseiam no levantamento sobre o número e o tipo de organizações envolvidas em decisões governamentais. Tornam-se centrais, entre outras variáveis, as regras operacionais já estabelecidas, características culturais das organizações, eficiência de implementação e de transmissão de ordens até os executores e os interesses de sobrevivência e expansão das burocracias. Percebe-se que já aí há uma qualificação do caráter racional das decisões de política externa de um país, uma vez que elas são orientadas por estímulos não necessariamente convergentes com o interesse nacional.

O Modelo III sofistica ainda mais a análise do processo decisório, uma vez que, em vez de assumir que as escolhas organizacionais prevalecem automaticamente na política a ser adotada, adiciona mais um fator de disputa: a barganha entre os responsáveis pela tomada de decisão. Entra-se, assim, em um campo de disputa política em que a hierarquia e o entrelaçamento de arenas exercem um papel determinante: as decisões são tomadas, em última instância, por "players who make government decisions not by a single, rational choice but by the pulling and hauling that is politics". Adentra-se, assim, no campo dos fatores que formam a percepção do decisor, incluindo a responsabilidade de um cargo específico ou o posicionamento do operador político em relação a 
seus pares.

Cabe destacar que, de acordo com o modelo proposto pelos autores, o Presidente não é um ator preponderante, senão um chefe entre outros chefes, ainda que mais influente (Rosati, 1980, p. 238). Este ponto causou críticas por parte de pesquisadores que acreditam haver maior espaço para atuação presidencial, de modo que sua caracterização como um líder com pouco a fazer diante de burocracias e procedimentos operacionais pré-estabelecidos soasse politicamente conveninente em casos de omissão do chefe do Executivo(Krasner, 1972, p. 162).

A articulação entre liderança presidencial e pressão burocrática também é lembrada por Hermann (1990). Ao buscar identificar os fatores determinantes de mudanças em política externa, o autor distingue quatro categorias influentes: o líder, a burocracia, reestruturação doméstica e choques externos. As duas primeiras categorias são as mais relevantes para este trabalho.

Líderes são capazes de alterar o curso da política externa de um país por meio da imposição de sua visão. Claro está que o sucesso de sua ação está condicionada à existência de "conviction, power and energy to compel his government to change course" (p. 11). As burocracias, por sua vez, são caracterizadas primeiramente como elementos de resistência à mudança de política externa, em consonância com a crítica de Krasner ao modelo de barganha 
inter-burocrática de Allison. Há a possibilidade, porém, de que determinadas burocracias (e não todas, em conjunto) assumam a bandeira da mudança em favor de sua valorização. O sucesso dessas agências depende principalmente, segundo o autor, do acesso a oficiais de alto nível capazes de operar ou influenciar efetivamente a mudança desejada

Modelos de interaçao estratégica assumem que tomadores de decisão são indivíduos agindo isoladamente. O pressuposto é forte o suficiente para dominar as metáforas que descrevem os modelos mais comuns em Teoria dos Jogos: Dilema do Prisioneiro, Jogo do Galinha, Ultimato, Jogo do Ditador, Leilões. Para além dos modelos introdutórios, os axiomas que fornecem o fundamento analítico de tomada de decisão parecem impor, ainda que tacitamente, a ideia de um ator individual. A ação racional é definida pela identificação de um objetivo bem definido, pelo elencamento de estratégias disponíveis e pela habilidade do tomador de decisão de hierarquizar essas estratégias de acordo com o critério de maximização de utilidade. Tais características são mais facilmente atribuídas a indivíduos do que a grupos de pessoas tomando decisões em conjunto.

Há motivos para que assim seja. Testes empíricos confirmam e reforçam alguns dos resultados previstos por modelos teóricos centrados no indivíduo, de modo que a predominância do ator individual na literatura analítica foi ado- 
tada também na literatura experimental. Até muito recentemente, simulações de situações que envolvem ação estratégica com frequência se concentraram na atuação de atores individuais. Camerer (2003, p. 475), em seu livro sobre aplicaçoes experimentais de modelos derivados da Teoria dos Jogos, nos informa que "virtually all of the experiments described in this book maintained a standard hypothesis in game theory (...). Most experiments just made individual subjects responsible for their own decisions. But labs are certainly flexible enough to permit experiments in which subjects are, say, teams, to seehow decision making differs". A distinção entre indivíduos e grupos é largamente ignorada na literatura.

Ainda assim, diversas das situações que esses modelos buscam compreender envolvem decisões tomadas em conjunto. Nas ciências sociais, indivíduos não são os únicos atores. Também o são famílias, comitês, partidos, tribunais, empresas e Estados. A suposição de que decisões tomadas em colegiado são analiticamente equivalentes àquelas tomadas por indivíduos pode dar conta da discrepância que se encontra entre resultados esperados e resultados observados para alguns modelos ${ }^{1}$.

\footnotetext{
${ }^{1}$ A literatura que descreve diferenças entre o comportamento predito e o comportamento real de atores é vastíssima, responsável por boa parte de uma disciplina inteira: a behavioral game theory. Não se pretende dar conta desse debate neste trabalho, mas jogos nos quais há observaçao sistemática de indivíduos adotando estratégias sub-ótimas incluem o Jogo do Ulti-
} 
Fora da Teoria dos Jogos, a constatação de que grupos se comportam de maneira diferente de indivíduos é bem estabelecida. Grupos têm a capacidade de contrabalançar vieses, mitigar falsas concepções entre seus membros e propiciam oportunidade para que erros de avaliação sejam identificados (Davis, 1992). Os efeitos positivos de decisões em grupo formam parte significante das justificativas para a criação de órgãos colegiados.

Não há consenso, porém, de que esses efeitos sejam sempre positivos. Asch (1956) é um experimento clássico de como indivíduos se sentem constrangidos a agir em conformidade com uma maioria, ainda que saibam que estão certos. Grupos podem estigmatizar outsiders, censurar opiniões dissonantes e conferir unânime legitimidade a decisões erradas, e esse risco é ainda maior quando há presença de um líder. Kocher and Sutter (2005) afirmam que grupos tendem a produzir melhores resultados do que indivíduos em jogos com soluções claras, em oposiçao àqueles que envolvem dilemas morais. Kerr et al. (1996) concluem que não existe resposta definiva à questão "grupos são mais enviesados que indivíduos?"

Schopler and Insko (1992), por sua vez, identificam um "efeito de descontinuidade"quando são comparadas interações entre grupos e interações entre mato, o Dilema do Prisioneiro e o Beauty-Contest Game (Bornstein and Yaniv, 1998). Para uma discussão mais detalhada, conferir Kahneman and Tversky (1979) e Kahneman (2013) 
indivíduos. Em um mesmo jogo, interação inter-grupos tende a ser muito mais competitiva do que a interaçao inter-indivíduos. Os autores oferecem duas explicações para o fenômeno: quando em grupo, pessoas tendem a identificar e suportar mutuamente interesses comuns, reforçando resultados egoístas. Uma explicação alternativa, porém relacionada, é que grupos agem de maneira defensiva: eles identificam no grupo adversário a disposição de agir egoisticamente, e são incentivados a responder à altura.

Simulando um Jogo de Ultimato, Bornstein and Yaniv (1998) concluem que grupos são mais eficientes ${ }^{2}$ do que indivíduos, na medida em que fazem demandas mais rigorosas do que jogadores individuais. De forma equivalente, grupos rejeitam com maior frequência ofertas consideradas muito baixas, apoiando a hipótese de que são mais competitivos do que indivíduos. Assim, grupos, em comparação com indivíduos, oferecem uma aproximação mais completa da estratégia ótima do modelo. Kugler et al. (2007) comparam resultados de grupos e indivíduos em Jogos de Confiança (Trust Games), concluindo que os primeiros tendem a confiar menos nos parceiros e escolhem enviar quantias menores de recursos.

Por fim, Kocher and Sutter (2005) simulam um Beauty-Contest Game $e^{3}$ no

\footnotetext{
${ }^{2}$ Os autores preferem dizer que grupos são mais "racionais".

${ }^{3} \mathrm{O}$ nome deste jogo é inspirado por uma observação de John Maynard Keynes sobre o mercado de ações: assim como em um concurso de beleza, um ator que queira fazer previsões
} 
qual também são comparadas as performances de grupos e indivíduos. Quando são jogadas diversas rodadas do jogo, grupos se destacam por aprender mais rapidamente o equilíbio e se aproximar dele com maior eficiência. Ademais, quando grupos competem contra atores individuais, têm resultados sistematicamente melhores. Bonacich et al. (1976) separaram 90 estudantes em grupos de 3, 6 e 9 pessoas, atribuindo a cada um deles a oportunidade de "cooperar"ou "não cooperar"em uma série de cenários. Os resultados surpreendem na medida em que se observou uma correlação positiva entre tamanho do grupo e cooperação.

\subsection{Interesses dos Doadores}

(Simplice, 2012) invertem a questão da eficácia da ajuda, ao perguntar em que medida o fracasso da ajuda pode contribuir para o padrão de doação de oaíses industrializados. Eles encontraram evidências de que a ajuda bilanão pode se limitar ao seu próprio julgamento de quem é mais provável que ganhe; não basta sequer imaginar quem o outros atores acham que ganha. É preciso se antecipar também à antecipação dos demais atores, de modo recursivo. Um exemplo comum deste jogo é pedir que alunos adivinhem um número de 0 a 100, e declarar que o ganhador será aquele que mais se aproximar da média da sala. Atores racionais tentarão se antecipar recursivamente, e, em equilíbrio, jogarão sempre 0 . Evidências experimentais apontam que é muito raro que algum ator jogue o valor ótimo (Nagel, 1995). 
teral é, acima de tudo, doada em conformidade com considerações políticas e estratégicas, preterindo a forma como o recurso é aplicado: sobre sistemas de saúde, em programas de educação, etc. Ex-colônias, por exemplo, com pobres condiçoes institucionais, recebem mais ajuda do que não-colônias em melhores condições de aplicar os recursos.

Com o mesmo argumento, (Vreeland, 2011) e (Signorino, 1999) afirmam que a eficácia da ajuda depende dos interesses estratégicos dos doadores. Se os doadores têm um grande interesse estratégico no país recipiendário, a ajuda será menos eficaz, já que os doadores não podem fazer ameaças críveis sobre as consequências de não adequação às condicionalidade sco empréstimo. A imposição de condicionalidades não seria, assim, um instrumento relevante para aumentar a qualidade do investimento em ajuda externa.

(Salois) destaca a importância de identificar sob que condições a condicionalidade da ajuda é bem sucedida. Ela conclui que contribuições do FMI e do Banco Mundial (multilateral), de fato, promovem a reforma fiscal, mas apenas em países mais democráticos. Ela argumenta que a vontade governos beneficiários de cumprir com as condições políticas depende do grau em que elas promove a sua sobrevivência política; uma vez que o impacto da ajuda na sobrevivência do governo aumenta com o nível de democracia do país beneficiário, a capacidade de resposta dos governos às condicionalidades reforça 
suas instituições democráticas.

O argumento de (Sartori, 2003) baseia-se no modelo político sobrevivência de Bueno de Mesquita et al (2003), qsegundo o qual a ajuda aumenta a probabilidade de sobrevivência para um regime autocrático, enquanto que o fluxo corrente de ajuda aumenta a probabilidade de líderes nos regimes democráticos. Isso faz com que os líderes autocráticos sejam menos dependente da ajuda, e, como conseqüência, lhes fornece menos incentivos para cumprir as condiçionalidades da ajuda.

\subsection{Doadores Emergentes}

De acordo com (Prather, 2011), seguindo (Shapiro et al., 2004), há uma revolução silenciosa acontecendo na ajuda para o desenvolvimento internacional, com um aumento do número doadores emergentes silenciosamente oferecendo alternativas para ajudar os países recipendários. Mais de 30 países doadores operam por fora do Development Assistance Committee (DAC), o órgão que coordena as açoes de ajuda externa de países desenvolvidos. De fato, vários doadores não pertencentes ao DAC não são tão novos na cooperação para o desenvolvimento internacional. Manning (2006, 384 p.) ressalta que muitos deles têm "uma boa dose de experiência."Alguns doadores doam ajuda para a África há mais de meio século (Kragelund, 2008). No entanto, A evidência em- 
pírica sobre se e como a atribuição de ajuda de países externos ao DAC difere da ajuda DAC é escassa e predominantemente descritiva.

A ajuda externade doadores desenvolvidos é na maioria das vezes condicional Prather (2011). A pobreza e as necessidades humanitárias nos países beneficiários são apenas um fator de definição da atribuição da ajuda. Condicionalidades associadas à ajuda DAC, seja explicita ou implicitamente, podem assumir duas formas Grieco et al. (1993): por um lado, os doadores exigem dos destinatários atos de apoio econômico ou político como um quid pro quo, por exemplo, investindo a ajuda ajuda em bens e serviços do doador ou suportando o doador em alguma votação relevante. Por outro lado, os países recipiendários são convidados a perseguir políticas econômicas específicas e à criar estruturas de governança que doadores considerem necessárias.

(Morrow, 1994)ao expor a discussão sobre a compatibilidade entre instituições democráticas e a formulação da política externa, Lima chama atenção para o fato de que "[o] tema da irracionalidade da 'opinião pública' e, por consequência, a antinomia democracia-política externa constitui parte ponderável da crítica de George Kennan à diplomacia norte-americana do século XIX à primeira parte do século $X X^{\prime \prime}$ (2000, p. 272). A influência em assuntos de política externa de uma massa pouco engajada nos assuntos da high politics, sem conhecimento detalhado de história diplomática e "que uma vez provocada reage 
de forma agressiva e irracional" é enxergada como uma ameaça aos interesses de sobrevivência e reprodução do Estado, ademais de constituir um caminho analítico pouco promissor para compreender as relações entre os Estados Ferraz and Finan (2009).

Outra corrente da literatura sobre o comportamento dos Estados no plano internacional, no entanto, chama a atenção para as limitações das abordagens sistêmicas, demasiado concentradas nos determinantes internacionais de comportamento estatal. Os autores que se contrapõem a essa abordagem se inscrevem em uma linha de pesquisa que busca valorizar a importância de traços característicos da política doméstica, particularmente no que diz respeito aos processos de tomada de decisão, para explicar o comportamento dos Estados. Os estudos consagrados na disciplina que se convencionou chamar de Análise de Política Externa buscam compreender os mecanismos que formam a estrutura de incentivos dos atores que definem o output da política externa de um Estado, dando especial importância para os processos de tomada de decisão (Hill, 2003, p.4).

A reação à abordagem sistêmica das relações internacionais acabou por produzir, a partir de meados dos anos 50, uma agenda de pesquisa radicalmente oposta à ideia de que constrangimentos externos eram determinantes para compreender a ação dos Estados na arena internacional. Influenciados 
sobretudo pela "revolução behaviorista" que ganhou força nas ciências sociais norte-americanas a partir de meados do século passado, os estudiosos de Análise de Política Externa buscaram se afastar de interpretações históricas das interações entre os Estados e passaram a buscar relações robustas capazes de indicar causalidade entre mecanismos políticos domésticos e a ação externa do Estado (Neack et alii, 1995, p. 8). Assim, na medida em que as abordagens sistêmicas buscavam identificar grandes tendências de comportamento em um nível mais geral de manifestação internacional dos Estados, os estudiosos de Análise de Política Externa buscavam o micro-fundamento do processo decisório; onde os estudiosos de Relações Internacionais se dedicavam a longos ensaios de história diplomática, os adeptos da Análise de Política Externa adotavam uma postura cientificista, com modelos explicativos rigorosos e, substantivamente, pouco ambiciosos; e onde os realistas clássicos enxergavam uma estrutura de decisão razoavelmente consensual sobre a definição dos interesses nacionais do Estado, os estudiosos da Análise de Política Externa enxergavam barganhas desagregadas, sujeitas a conflitos potencialmente estranhos ao núcleo substantivo das questões que estavam sendo endereçadas. A relativa saturação das pretensões cientificistas dos estudiosos de Análise de Política Externa dos anos 1950 e 1960 abriu espaço para maior diversidade analítica a partir dos anos 1970. A Segunda Geração (Neack, 1995, p. 11) de pesquisadores 
de política externa buscou ativamente uma maior diversidade metodológica que a adotada por seus antecessores. Observa-se, então, a emergência de técnicas qualitativas capazes de apreender com maior profundidade os mecanismos que governam os processos de tomada de decisão, assim como maior recepção a modelos de explicação multicausais, mais complexos e menos rigorosos, do ponto de vista, das regras de produção de conhecimento científico, do que os estudos da geração anterior. Relativiza-se, também, a ênfase aos determinantes domésticos da política externa, e dá-se maior importância à dinâmica de influência mútua entre o ambiente internacional e o plano doméstico.

A contribuição dos estudos de Análise de Política Externa, particularmente pela aproximação que logrou operar entre estudiosos de Ciência Política e Relações Internacionais, é sentida nos estudos que dizem respeito à influência da opinião pública sobre o comportamento internacional dos Estados. A área de Ciência Política conta com uma profícua literatura que explora os efeitos das mudanças de opinião da população sobre a implementação de políticas públicas - tais como politicas de saúde, programas econômicos ou políticas de segurança. Um dos problemas mais recorrentes dessa literatura, porém, é estabelecer com segurança o impacto da avaliação popular sobre as ações governamentais. Burstein (2003) afima que a maioria dos pesquisadores concordaria que "(1) public opinion influences public policy; (2) the more salient an issue 
to the public, the stronger the relationship is likely to be; and (3) the relationship is threatened by the power of interest organizations" (p. 29). Entretanto, há muito menos consenso sobre questões como a intensidade do impacto ou a homogeneidade, no decorrer do tempo, da reação do governo às pressões da população. Analisando pesquisas de opinião de diferentes áreas temáticas, Burstein conclui que há grande intensidade no efeito da opinião pública sobre a implementação de políticas e, mais importante para o presente trabalho, não há distinção siginificativa entre o impacto em políticas domésticas e internacionais. De fato, "on defense, government is more responsive to the public than on other policies, not less"' (p. 36). Aldrich et alii (2006), por sua vez, reforçam a hipótese da "normalidade" da avaliação da política externa por parte da opinião pública ao constatar que os eleitores mantêm posições consistentes sobre política externa e as utilizam para premiar ou punir candidatos que se aproximam ou se afastam de suas preferências. Os autores não encontram evidências claras, porém, de que o posicionamento do público resultou em redirecionamento das propostas de política externa por parte dos partidos, de modo que a "conexão eleitoral" entre opinião pública e política externa ainda ficou para ser estabelecida com firmeza.

(Pehnelt, 2007), por fim, revela com maior sofisticação a relação entre opinião pública e partidos políticos: analisando dados eleitorais de 1980 a 2004 nos 
Estados Unidos, a autora conclui que eleitores republicanos são mais sensíveis a questões de política externa do que seus pares Democratas. Consequentemente, candidatos conservadores recebem incentivos para dedicar mais atenção a questões de política externa do que os liberais, revelando que, ainda que a opinião pública seja capaz de influenciar decisões de política externa, há assimetrias de perfis sociais demográficos que precisam ser levados em consideração. A experiência americana nos conduz à questão: terá a opinião pública sobre política externa no Brasil um impacto eleitoral semelhantemente significativo? Em outras palavras: a avaliação da política externa é um bom preditor de escolha de candidato? 


\section{A Cooperação Brasileira}

A estratégia de inserção internacional do Brasil é um dos temas que mais chamam a atenção dos pesquisadores de política externa e relações internacionais nos últimos anos. O tema da cooperação sul-sul tem ganhado força, particularmente no que se refere à participação do país em coalizões de países emergentes em fóruns multilaterais. Uma faceta menos notada dessa tendência, entretanto, é o investimento brasileiro em ajuda internacional, tanto em projetos em países pobres quanto no fortalecimento da própria estrutura burocrática interna que os gerencia.

Em oposição às modalidades tradicionais de cooperação internacional, que são acordadas entre países com diferentes níveis de desenvolvimento econômico e diferentes interesses estratégicos, a cooperação Sul-Sul se caracteriza por envolver países em desenvolvimento, com maior potencial de identificação mútua e de convergência de interesses. Não surpreende, portanto, que essa modalidade tenha ganhado força ultimamente, na medida em que países emergentes alcançam projeção internacional e se encontram em condições mais favoráveis para fortalecer laços diplomáticos, promover o desenvolvimento econômico de parceiros comerciais (efetivos ou potenciais) e aumentar, quantitativa e qualitativamente, sua influência no âmbito internacional. 
No Brasil, o órgão responsável pela articulação dos acordos de cooperação internacional é a Agência Brasileira de Cooperação, vinculado ao Ministério das Relações Exteriores. Sua criação, em 1987, acompanhou o processo de abertura democrática do país e sua atuação já atravessa sete mandatos presidenciais tão variados em suas orientações políticas quanto nos contextos externos que eles enfrentaram. A compreensão de sua relevância estratégica na política externa brasileira não acompanhou, entretanto, a atenção que a Agência Brasileira de Cooperação tem ganhado por parte do governo federal.

\subsection{Conflito e Cooperação em Projetos de Desenvolvimento In-}

\section{ternacional}

As discussões centrais sobre cooperação encontram base na década de 1970, em autores que sintetizam o debate entre neorrealistas e neoliberais, particularmente em sua vertente institucionalista. Em comum, esses autores tomam a cooperação como instrumento para aumentar seus ganhos individuais. Em diversos pontos, entretanto, pesquisadores alinhados às duas perspectivas apresentam divergências siginificativas. David Baldwin (1993, p. 4) organiza o debate conhecido como neo-neo em seis pontos focais, quais sejam: a importância da anarquia, a possibilidade de cooperação internacional, a preponderância de ganhos relativos ou ganhos absolutos, a prioridade dos objetivos dos Esta- 
dos, as tensões entre intenção e capacidade e o papel de instituições e regimes internacionais. Observemos brevemente como neorrealistas e neoinstitucionalistas se posicionam nos temas mais relevantes para os fins deste trabalho. A constatação da ausência de uma autoridade central legítima de caráter global é cara aos neorrealistas (e ao realismo clássico) por ser uma das características basilares que distinguem a política internacional da política doméstica. Apesar de não desafiarem a existência dessa anarquia, os institucionalistas neoliberais tendem a considerá-la apenas mais um entre diversos fatores a serem analisados, inclusive aqueles que promovem os canais de cooperação e interdependência. Em uma exaustiva análise do conceito de anarquia e de seu uso nas teorias de relações internacionais, Helen Milner conclui: “while anarchy is an importante condition of world politics, it is not the only one" (1993, p. 167).

Os debates relativos à possibilidade de cooperação internacional e à importância de ganhos relativos e ganhos absolutos, por sua vez, podem ser considerados conjuntamente: neoliberais institucionalistas acreditam que Estados se orientam por ganhos absolutos, de modo que fica favorecida a possibilidade de cooperação em instituições internacionais que promova ganhos mútuos para os participantes. Neorrealistas, por sua vez, defendem que Estados dão ênfase a ganhos relativos, estando dispostos a deixar de obter mais vantagens na medida em que possam interferir nas vantagens obtidas pelos demais. 
As linhas teóricas tradicionais não identificam os eventuais incentivos dos países menos desenvolvidos em promover a cooperação, tampouco iluminam a forma como se dá a interação desses interesses com a) os interesses dos países mais desenvolvidos, ou mesmo com b) os interesses dos demais países nãodesenvolvidos. Assim, uma linha de análise baseada na escolha racional tem chamado a atenção para a importância de se identificar os padrões de incentivos que se oferecem aos atores internacionais para adotar uma postura menos conflituosa em suas interações.

Deve-se reconhecer, neste sentido, a original contribuição do livro "The Evolution of Cooperation", de Robert Axelrod (1984). Por meio de uma série de reproduções reiteradas do Dilema do Prisioneiro, Axelrod buscou responder a "uma simples pergunta: quando deve uma pessoa cooperar e quando uma pessoa deve ser egoísta em uma interação contínua com uma outra pessoa" (p. 7)?

O problema, de alcance sociológico amplo, provou ser proveitosamente aplicável nas interações entre os atores das Relações Internacionais, particularmente entre Estados que se relacionam sem a presença de uma entidade hierarquicamente superior capaz de arbitrar entre seus diferentes interesses. A resposta encontrada pelo autor à pergunta original é admiravelmente simples: a estratégia mais efetiva em uma interação contínua entre dois atores é coo- 
perar na primeira oportunidade e, nas interações seguintes, reproduzir a ação anterior do outro ator. A essa estratégia de cooperação caracterizada pela reciprocidade deu-se o nome de TIT FOR TAT. Pode-se, como argumenta o autor, atribuir a ela a emergência de cooperação nos contextos em que esta seria a estratégia menos esperada, como a "cooperação entre antagonistas observada nas guerras de trincheiras da Primeira Guerra Mundial" (p. 87). A cooperação, ressalta o autor, não requer amizade, senão a existência de objetivos comuns.

Nesta mesma linha, Keohane e Axelrod (1985) sublinham que cooperação não implica harmonia completa, tampouco é necessariamente boa quando analisada de um ponto de vista moral. Os autores identificam duas arenas principais nas quais se aplicam as estratégias de cooperação e conflito nas relações internacionais: a) aquela na qual se discutem questões militares e de segurança e b) aquela na qual se discutem questões políticas e econômicas ( p. 232). Apesar de possuírem dinâmicas de interação diferentes, os autores defendem que é possível identificar uma estrutura de incentivos comum a ambas, organizando os padrões de cooperação e conflito na esfera internacional em conjunção com uma série de fatores conjunturais que se acomodam, de diferentes maneiras, no quadro mais amplo das estruturas de interação. Vê-se assim que a inexistência de um governo global comum não significaria a inexistência de uma sociedade internacional, ainda que fragmentada pela existência de variados con- 
textos.

As três dimensões estruturais da cooperação identificadas por Keohane e Axelrod são: a) a mutualidade de preferências, estabelecendo que quanto maior o conflito de interesses entre dois atores, maior é a possibilidade de eles não cooperarem; b) a "sombra do futuro", ou seja, a expectativa da reiteração das relações entre países, que constituiria um incentivo à cooperação por meio da combinação entre perspectiva de longo prazo e a crescente transparência de dados que informam as decisões estratégicas; e c) o número de atores envolvidos, estabelecendo que, quanto maior o número de atores simultâneos no jogo, mais difícil é identificar atores não-cooperativos e, por consequência, puni-los, diminuindo a chance de a cooperação produzir resultados positivos (p. 227). O paradigma teórico oferecido por Keohane e Axelrod fornece uma linha de investigação promissora para compreender a evolução das políticas de cooperação internacional promovidas por países não desenvolvidos, na medida em que reconhece em todos os atores, e não apenas naqueles em posição de domínio, a existência de incentivos para empreender ações em conjunto.

Estabelecidas as condições sob as quais diferentes países cooperam, fazse necessário analisar os mecanismos que impulsionam suas ações. No que diz respeito ao enquadramento dos fatores que motivam as ações dos países no âmbito externo, os trabalhos desenvolvidos com foco na formulação da política 
externa se posicionam de modo a sublinhar a importância dos conflitos políticos domésticos na formulação de escolhas e no processo de tomada de decisão. Contrapõe-se, assim, ao arcabouço teórico que se desenvolveu na primeira metade do século XX, particularmente pelos teóricos realistas, que se baseava na relação entre Estados unitários, estes tomados como atores coerentes agindo racionalmente com o fim satisfazer o "interesse nacional".

Graham Allison e Philip Zelikov defendem, em "Essence of Decision" (1999), a importância de se levar em consideração os estímulos e interesses organizacionais envolvidos em uma decisão com impacto externo - no caso dos autores, a reação americana ao episódio dos mísseis em Cuba. Os autores desenvolvem três modelos, cada um com bases conceituais próprias, a partir dos quais uma série de proposições são deduzidas e comparadas com os registros históricos. Deste modo, o Modelo I, de governo unitário, se concentra nos objetivos do Estado, nas estruturas de custos e ganhos potenciais na tomada de decisão e na percepção, com base nessas informações, da melhor estratégia a ser adotada.

O Modelo II, por sua vez, toma como atores principais as burocracias envolvidas na formulação da política. Segundo os autores, “in Model II explanations, the subjects are never named individuals or entire governments. Rather, the subjects of Model II are organizations, and their behavior is explained in 
terms of organizational purposes and practices common to the members of the organization, not those particular to one or another individual" (p. 145). Assim, as deduções originadas do Modelo II se baseiam no levantamento sobre o número e o tipo de organizações envolvidas em decisões governamentais. Tornam-se centrais, entre outras variáveis, as regras operacionais já estabelecidas, características culturais das organizações, eficiência de implementação e de transmissão de ordens até os executores e os interesses de sobrevivência e expansão das burocracias. Percebe-se que já aí há uma qualificação do caráter racional das decisões de política externa de um país, uma vez que elas são orientadas por estímulos não necessariamente convergentes com o interesse nacional.

O Modelo III sofistica ainda mais a análise do processo decisório, uma vez que, em vez de assumir que as escolhas organizacionais prevalecem automaticamente na política a ser adotada, adiciona mais um fator de disputa: a barganha entre os responsáveis pela tomada de decisão. Entra-se, assim, em um campo de disputa política em que a hierarquia e o entrelaçamento de arenas exercem um papel determinante: as decisões são tomadas, em última instância, por "players who make government decisions not by a single, rational choice but by the pulling and hauling that is politics". Adentra-se, assim, no campo dos fatores que formam a percepção do decisor, incluindo a responsabilidade 
de um cargo específico ou o posicionamento do operador político em relação a seus pares.

Cabe destacar que, de acordo com o modelo proposto pelos autores, o Presidente não é um ator preponderante, senão um chefe entre outros chefes, ainda que mais influente (Rosati, 1980, p. 238). Este ponto causou críticas por parte de pesquisadores que acreditam haver maior espaço para atuação presidencial, de modo que sua caracterização como um líder com pouco a fazer diante de burocracias e procedimentos operacionais pré-estabelecidos soasse politicamente conveninente em casos de omissão do chefe do Executivo(Krasner, 1972, p. 162).

A articulação entre liderança presidencial e pressão burocrática também é lembrada por Hermann (1990). Ao buscar identificar os fatores determinantes de mudanças em política externa, o autor distingue quatro categorias influentes: o líder, a burocracia, reestruturação doméstica e choques externos. As duas primeiras categorias são as mais relevantes para este trabalho.

Líderes são capazes de alterar o curso da política externa de um país por meio da imposição de sua visão. Claro está que o sucesso de sua ação está condicionada à existência de "conviction, power and energy to compel his government to change course" (p. 11). As burocracias, por sua vez, são caracterizadas primeiramente como elementos de resistência à mudança de polí- 
tica externa, em consonância com a crítica de Krasner ao modelo de barganha inter-burocrática de Allison. Há a possibilidade, porém, de que determinadas burocracias (e não todas, em conjunto) assumam a bandeira da mudança em favor de sua valorização. O sucesso dessas agências depende principalmente, segundo o autor, do acesso a oficiais de alto nível capazes de operar ou influenciar efetivamente a mudança desejada

\subsection{As Iniciativas Brasileiras}

A emergência do Brasil no cenário internacional tem chamado a atenção de alguns pesquisadores para seu papel como receptor e, mais recentemente, doador de iniciativas de cooperação internacional. Essa mudança no perfil de atuação do país evolui paralelamente ao recente reforço da imagem brasileira de potência emergente no cenário internacional. Após a crise econômica de 2008, o Brasil passou a ser um interlocutor privilegiado das iniciativas econômicas globais de contenção de seus efeitos, principalmente por meio do G20, grupo criado, a princípio, sem poderes de deliberação, mas que ganhou força com a necessidade de reconhecer o peso de economias emergentes na economia mundial. Aliado a isso, uma combinação de regulamentação bancária conservadora, acertadas iniciativas governamentais e grande demanda externa (particularmente aquela proveniente do mercado de commodities chinês) garan- 
tiu um bom desempenho da economia brasileira em uma época de depressão econômica na maioria das economias centrais. O Brasil fincou mais profundamente suas raízes de potência no solo da economia mundial.

A esses fatores conjunturais se soma uma orientação deliberada do Estado brasileiro no sentido de ampliar sua presença internacional por meio de iniciativas de cooperação técnica. A revista "The Economist" identifica o Brasil como um dos maiores "provedores de ajuda" para países pobres, investindo, em 2010, um valor de aproximadamente 4 bilhões de reais em iniciativas que se estendem de empréstimos do BNDES à cooperação técnica por meio da Embrapa e ao apoio militar no Haiti. Nesta frente de atuação internacional, observa-se a preferência dada a acordos de cooperação sul-sul, ou seja, a cooperação com países em desenvolvimento.

A literatura identifica o início do governo Lula como um ponto de inflexão nas iniciativas de cooperação internacional encetadas pelo Brasil. Alden e Vieira (2005) observam que a partir de 2003 houve um esforço concertado no sentido de "cortejar" Estados da África, do Leste Asiático e, particularmente, a China, em contraste com uma 0perspectiva americanista com raízes nos anos 1960 e que teria dado o tom da política externa brasileira, em maior ou menor intensidade, até os governos de Fernando Henrique Cardoso.

Vigevani e Cepaluni (2007) argumentam, ancorados no modelo de avali- 
ação de mudanças política externa de Hermann (1990), pela existência de três períodos distintos na diplomacia brasileira, quais sejam: a "autonomia pela distância", vigente até o governo Sarney, a "autonomia pela participação", nos mandatos de Fernando Henrique Cardoso e a "autonomia pela diversificação" durante o governo Lula. Os autores sintetizam os traços característicos de cada período:

Definimos sinteticamente: (1) “autonomia pela distância" como uma política de não-aceitação automática dos regimes internacionais prevalecentes e, sobretudo, a crença no desenvolvimento parcialmente autárquico, voltado para a ênfase no mercado interno; consequentemente, uma diplomacia que se contrapõe a certos aspectos da agenda das grandes potências para se preservar a soberania do Estado Nacional; (2) "autonomia pela participação" como a adesão aos regimes internacionais, inclusive os de cunho liberal, sem a perda da capacidade de gestão da política externa; nesse caso, o objetivo seria influenciar a própria formulação dos princípios e das regras que regem o sistema internacional; (3) "autonomia pela diversificação" como a adesão do país aos princípios e às normas internacionais por meio de alianças Sul-Sul, inclusive regionais, e de acordos com parceiros não tradicionais (China, Ásia-Pacífico, África, Europa Oriental, 
OrienteMédio etc.), pois acredita-se que eles reduze mas assimetrias nas relações externas com países mais poderosos e aumentam a capacidade negociadora nacional

Temos, assim, que a chegada do Partido dos Trabalhadores ao poder representou, segundo os autores um realinhamento da política externa do país, mas não constituiu um rompimento (p. 322) Lima e Hirst (2006), por sua vez, identificam, na evolução das ideias que definiram a conduta exterior brasileira a partir de meados do século XX, duas abordagens distintas competindo por espaço e influência nos escalões mais altos do Itamaraty: o primeiro, chamado de "busca de credibilidade", teria prevalecido nos governos de Fernando Henrique Cardoso e priorizaria uma linha de ação orientada pela percepção externa sobre o Brasil (p. 24). O país não teria, segundo os defensores desta abordagem, condições de fazer valer seus interesses por meio do uso exclusivo da força e dependeria, como consequência, do fortalecimento de instituições internacionais nas quais faria valer seu poder de influência. Como corolário, a agenda internacional brasileira teria pouca autonomia interna e se esforçaria por se enquadrar em recomendações internacionais de atuação e regulamentação. Contrapor-se-iam a esses formuladores os proponentes da política externa com ênfase na autonomia, com um esforço de projeção explicitamente autóctone. Segundo as autoras, esta visão teria prevalecido, ainda que não completa- 
mente, no governo Lula, e seria a responsável pelo aumento dos investimentos brasileiros em esforços de cooperação sul-sul, dos quais seriam exemplos mais notáveis a iniciativa do IBSA e o comando das forças de pacificação da ONU no Haiti.

Pecequilo (2008) ecoa esta visão ao identificar uma mudança de foco da política externa brasileira a partir do governo Lula, com a manutenção do “Eixo Vertical" da política externa, ou seja, as relações estabelecidas com os países desenvolvidos, e o concomitante fortalecimento do "Eixo Horizontal", que é constituído pelas relações com países não-desenvolvidos. A autora aponta que a percepção oficial brasileira é a de que a recente mudança no eixo privilegiado das relações exteriores já produziu resultados positivos, de cuja evidência seria o desempenho da economia brasileira durante a crise de 2008. A autora cita o Ministro Celso Amorim: "Pegue um economista como o Albert Fishlow (da Columbia University). Em entrevista recente ele disse que o desenvolvimento dessas relações Sul-Sul é uma das razões pelas quais o Brasil encontra-se menos vulnerável aos problemas na economia americana" (p. 147).

Lima (2005), valorizando a questão da identidade na inserção internacional, relembra o status de "system-affecting state" que tinham países como Brasil, Índia e México na década de 1970. Segundo a autora, o Brasil vem tentando se posicionar no cenário internacional como um país em desenvolvimento sem 
perder a condição de país capaz de provocar mudanças significativas na esfera internacional (p. 3). Ainda que a existência de um centro de formação e socialização de diplomatas provoque alguma estabilidade na condução da política externa brasileira (p. 7), a autora identifica, em consonância com o restante da literatura, uma mudança de inclinação na política externa brasileira a partir do governo Lula, partindo da estratégia de "credibilidade" vigente no governo Fernando Henrique Cardoso para a estratégia de "autonomia": "a principal diferença entre os dois governos é de perspectiva, da visão internacional de cada um deles" (p. 12). Tal diferença, no entanto, significa um afastamento da identidade de emergente, associada à estratégia de "credibilidade" e uma aproximação da identidade de "system-affecting state", associada à estratégia de “autonomia" (p. 13)

Em uma perspectiva histórica mais ampla, Cervo (1994) identifica na ação diplomática brasileira dos anos 1930 aos anos 1990 uma atuação que se orienta "invariavelmente para a promoção do desenvolvimento nacional". Escrevendo antes da eleição do governo Lula e, portanto, em um contexto no qual o fluxo de cooperação internacional no país era mais centrípeto do que centrífugo, Cervo considera que o conceito de cooperação internacional no Brasil foi articulado em torno de três eixos básicos: o do significado político, que, com a pretensão de sintetizar a política externa brasileira na palavra "cooperação", preten- 
dia sublinhar o viés não-bélico do país na arena internacional; o dos objetivos econômicos, entre eles o de fortalecer a política de substituição de exportações nos anos 1960 e o de aumentar a capacidade técnico-científica do país por meio de acordos com países industrializados; e, por fim, o do modus faciendi, que, nas palavras do autor, constituía "uma cooperação desideologizada, até mesmo despolitizada, que explorava oportunidades com realismo, que criava alternativas diante de obstáculos" (p.6).

Observa-se, assim, que a literatura identifica no conjunto de iniciativas brasileiras de cooperação internacional um instrumento que não só atende a interesses táticos para a obtenção de resultados específicos, mas que se subordina também a uma percepção estratégica da forma de inserção de longo prazo do país no cenário internacional. Podemos estender essa ideia para dizer que a cooperação internacional constitui parte do arsenal brasileiro de aplicação de seu soft power, definido por Joseph Nye (2004) como o exercício da influência sobre os demais atores pela atração, em oposição à coerção. O fato de o governo Lula ser percebido como realizador de transição entre "potência regional discreta" para uma "potência de liderança cooperativa" (Gratius, 2004) não pode ser desvinculado de uma estratégia de inserção internacional que envolve a) um fluxo cada vez maior de doação de cooperação em função de um fluxo decrescente de recebimento de cooperação e b) um envolvimento cada vez maior 
com países não-desenvolvidos e em desenvolvimento em prejuízo de países desenvolvidos.

\subsection{A Agência Brasileira de Cooperação}

A Agência Brasileira de Cooperação foi criada, em setembro de 1987, com o fim de atender à necessidade de coordenar os esforços de cooperação no âmbito do Estado Brasileiro, servindo-se de recursos orçamentários dirigidos e da infraestrutura institucional necessária para operar a articulação entre os diferentes temas de cooperação. A agência é dividida em sete coordenações que abrangem desde infra-estrutura até temas relacionados à área social

Iglesias (2010) identifica esta instituição como "o ponto focal de toda a cooperação técnica brasileira" (p. 130) e chama a atenção para o fato de que ela, diferentemente de instituições semelhantes financiadas por países desenvolvidos, possui um caráter duplo: se encarrega tanto de acordos de cooperação recebida (de outros países ou de órgãos multilaterais, de que se ocupam primordialmente a Comissão Geral de Cooperação Técnica Recebida Bilateral e a Comissão Geral de Cooperação Técnica Recebida Multilateral) quanto de cooperação doada (a países em desenvolvimento, finalidade principal da Comissão Geral de Cooperação Técnica entre Países em Desenvolvimento). O autor destaca a crescente importância que o Estado brasileiro tem dado às iniciati- 
vas de cooperação sul-sul: “Outra ressalva importante é a de que a ABC está passando, desde o início de 2007, por uma reformulação interna, a qual tem por objetivo justamente fortalecer a área de CTPD [Cooperação Técnica para o Desenvolvimento], que será tomada em devida conta especialmente na análise dos problemas e das potencialidades da CTPD brasileira." (p. 131). De igual relevância para a análise do papel da cooperação sul-sul no contexto mais amplo da política externa brasileira é a existência de uma coordenadoria especialmente destinada às relações com países em desenvolvimento.

Sob a perspectiva do fortalecimento da Agência Brasileira de Cooperação, vale notar que Iglesias destoa da percepção expressada na maioria dos estudos sobre a política externa brasileira, qual seja, a de que a posse de Lula a partir de 2003 representou um movimento sensível no sentido de fortalecer a atuação do Estado brasileiro nessa área. O autor identifica entre 1995 e 2005 “dois momentos bastante diversos: o do crescimento e expansão a agência (1995 a 2001) e o de seu desafio institucional (2002 a 2005)" (p.131). O primeiro seria marcado pelo crescimento do volume de acordos assinados (tanto no que diz respeito à cooperação dada quanto no que diz respeito à cooperação recebida) e pela concentração de tarefas e atribuições antes fragmentadas em diferentes setores governamentais. O segundo, por sua vez, antes de se caracterizar pelo aumento do número de acordos ou pela mudança na direção dos fluxos de co- 
operação, se marcaria, ainda segundo o autor, pela consolidação institucional e pela superação de dificuldades jurídicas relacionadas à sua atuação. Deste modo, quatorze anos depois de sua fundação, a agência começaria a reagir de modo mais intensivo contra obstáculos acumulados ao longo do tempo, impulsionada, entre outros motivos, por questionamentos de órgãos oficiais de fiscalização orçamentária (p. 134). Ademais, a agência passa, nesse segundo momento, a investir em recursos de infra-estrutura próprios, já que tradicionalmente ocupava as instalações de representações do Ministério de Relações Exteriores em outros países.

A crescente importância que o governo brasileiro vem dando ao relacionamento com países em desenvolvimento é exemplificada por Lopes (2008): enquanto entre 1995 e 2001 apenas 25\% das viagens presidenciais tinham esses países como destino, entre 2003 e março de 2006 esse número já tinha subido para 53,12\% (p. 120). Lopes nos alerta que esse aumento se deu de forma mais gradual do que a transição de lideranças políticas no período faria parecer, lembrando que, já no segundo mandato do presidente Fernando Henrique Cardoso, a proporção de viagens a países desenvolvidos começava a cair, principalmente devido a constrangimentos impostos na conjuntura internacional ("em especial a reação estadunidense aos ataques terroristas de setembro de 2001", p. 118). 
Assim, ao expor a discussão sobre a compatibilidade entre instituições democráticas e a formulação da política externa, Lima chama atenção para o fato de que “[o] tema da irracionalidade da 'opinião pública' e, por consequência, a antinomia democracia-política externa constitui parte ponderável da crítica de George Kennan à diplomacia norte-americana do século XIX à primeira parte do século XX" (2000, p. 272). A influência em assuntos de política externa de uma massa pouco engajada nos assuntos da high politics, sem conhecimento detalhado de história diplomática e "que uma vez provocada reage de forma agressiva e irracional" é enxergada como uma ameaça aos interesses de sobrevivência e reprodução do Estado, ademais de constituir um caminho analítico pouco promissor para compreender as relações entre os Estados.

Outra corrente da literatura sobre o comportamento dos Estados no plano internacional, no entanto, chama a atenção para as limitações das abordagens sistêmicas, demasiado concentradas nos determinantes internacionais de comportamento estatal. Os autores que se contrapõem a essa abordagem se inscrevem em uma linha de pesquisa que busca valorizar a importância de traços característicos da política doméstica, particularmente no que diz respeito aos processos de tomada de decisão, para explicar o comportamento dos Estados. Os estudos consagrados na disciplina que se convencionou chamar de Análise de Política Externa buscam compreender os mecanismos que formam a estru- 
tura de incentivos dos atores que definem o output da política externa de um Estado, dando especial importância para os processos de tomada de decisão (Hill, 2003, p.4).

A reação à abordagem sistêmica das relações internacionais acabou por produzir, a partir de meados dos anos 50, uma agenda de pesquisa radicalmente oposta à ideia de que constrangimentos externos eram determinantes para compreender a ação dos Estados na arena internacional. Influenciados sobretudo pela "revolução behaviorista" que ganhou força nas ciências sociais norte-americanas a partir de meados do século passado, os estudiosos de Análise de Política Externa buscaram se afastar de interpretações históricas das interações entre os Estados e passaram a buscar relações robustas capazes de indicar causalidade entre mecanismos políticos domésticos e a ação externa do Estado (Neack et alii, 1995, p. 8). Assim, na medida em que as abordagens sistêmicas buscavam identificar grandes tendências de comportamento em um nível mais geral de manifestação internacional dos Estados, os estudiosos de Análise de Política Externa buscavam o micro-fundamento do processo decisório; onde os estudiosos de Relações Internacionais se dedicavam a longos ensaios de história diplomática, os adeptos da Análise de Política Externa adotavam uma postura cientificista, com modelos explicativos rigorosos e, substantivamente, pouco ambiciosos; e onde os realistas clássicos enxergavam uma 
estrutura de decisão razoavelmente consensual sobre a definição dos interesses nacionais do Estado, os estudiosos da Análise de Política Externa enxergavam barganhas desagregadas, sujeitas a conflitos potencialmente estranhos ao núcleo substantivo das questões que estavam sendo endereçadas. A relativa saturação das pretensões cientificistas dos estudiosos de Análise de Política Externa dos anos 1950 e 1960 abriu espaço para maior diversidade analítica a partir dos anos 1970. A Segunda Geração (Neack, 1995, p. 11) de pesquisadores de política externa buscou ativamente uma maior diversidade metodológica que a adotada por seus antecessores. Observa-se, então, a emergência de técnicas qualitativas capazes de apreender com maior profundidade os mecanismos que governam os processos de tomada de decisão, assim como maior recepção a modelos de explicação multicausais, mais complexos e menos rigorosos, do ponto de vista, das regras de produção de conhecimento científico, do que os estudos da geração anterior. Relativiza-se, também, a ênfase aos determinantes domésticos da política externa, e dá-se maior importância à dinâmica de influência mútua entre o ambiente internacional e o plano doméstico.

A contribuição dos estudos de Análise de Política Externa, particularmente pela aproximação que logrou operar entre estudiosos de Ciência Política e Relações Internacionais, é sentida nos estudos que dizem respeito à influência da opinião pública sobre o comportamento internacional dos Estados. A 
área de Ciência Política conta com uma profícua literatura que explora os efeitos das mudanças de opinião da população sobre a implementação de políticas públicas - tais como politicas de saúde, programas econômicos ou políticas de segurança. Um dos problemas mais recorrentes dessa literatura, porém, é estabelecer com segurança o impacto da avaliação popular sobre as ações governamentais. Burstein (2003) afima que a maioria dos pesquisadores concordaria que "(1) public opinion influences public policy; (2) the more salient an issue to the public, the stronger the relationship is likely to be; and (3) the relationship is threatened by the power of interest organizations" (p. 29). Entretanto, há muito menos consenso sobre questões como a intensidade do impacto ou a homogeneidade, no decorrer do tempo, da reação do governo às pressões da população. Analisando pesquisas de opinião de diferentes áreas temáticas, Burstein conclui que há grande intensidade no efeito da opinião pública sobre a implementação de políticas e, mais importante para o presente trabalho, não há distinção siginificativa entre o impacto em políticas domésticas e internacionais. De fato, "on defense, government is more responsive to the public than on other policies, not less" (p. 36). Aldrich et alii (2006), por sua vez, reforçam a hipótese da "normalidade" da avaliação da política externa por parte da opinião pública ao constatar que os eleitores mantêm posições consistentes sobre política externa e as utilizam para premiar ou punir candidatos que se aproxi- 
mam ou se afastam de suas preferências. Os autores não encontram evidências claras, porém, de que o posicionamento do público resultou em redirecionamento das propostas de política externa por parte dos partidos, de modo que a "conexão eleitoral" entre opinião pública e política externa ainda ficou para ser estabelecida com firmeza.

Gadarian (2010), por fim, revela com maior sofisticação a relação entre opinião pública e partidos políticos: analisando dados eleitorais de 1980 a 2004 nos Estados Unidos, a autora conclui que eleitores republicanos são mais sensíveis a questões de política externa do que seus pares Democratas. Consequentemente, candidatos conservadores recebem incentivos para dedicar mais atenção a questões de política externa do que os liberais, revelando que, ainda que a opinião pública seja capaz de influenciar decisões de política externa, há assimetrias de perfis sociais demográficos que precisam ser levados em consideração. A experiência americana nos conduz à questão: terá a opinião pública sobre política externa no Brasil um impacto eleitoral semelhantemente significativo? Em outras palavras: a avaliação da política externa é um bom preditor de escolha de candidato?

Ademais, sendo o Brasil membro da Organização das Nações Unidas, seu compromisso em fomentar o desenvolvimento por meio de cooperação com países em desenvolvimento é reforçado pelos Objetivos do Milênio. Entre as 
metas estabelecidas pelo plano de ação do programa e a serem cumpridas até 2015, está a destinação de 0,7\% do PIB dos países desenvolvidos para a Assistência Oficial ao Desenvolvimento. Ainda que não esteja entre o grupo de países que devem corresponder a essa meta, e apesar dos crescentes aportes em cooperação internacional, o país investe $0,02 \%$ de seu PIB em projetos dessa natureza (Ipea, ABC, 2010, p. 19) e demonstra preocupação pela perspectiva de que ela possa ser descumprida (Ipea, 2010a, p. 155).

Temos, assim, que, para além de ter recebido cada vez maior atenção por parte do governo brasileiro, a Agência Brasileira de Cooperação ocupa uma posição privilegiada na articulação dos planos do país de inserção internacional no futuro. A percepção externa do Brasil como uma nação pacífica, de tradição não-intervencionista, revela-se um ativo crescentemente explorado não só pelos formuladores da política externa nacional, mas também almejado por países desenvolvidos que, por meio de parcerias de cooperação trilateral, têm interesse em se associar com o Brasil em projetos de desenvolvimento internacional. Outro indicador do reconhecimento por parte do governo federal da importância da Agência Brasileira de Cooperação para os objetivos de médio e longo prazos da política externa brasileira é o investimento no relatório “Cooperação para o Desenvolvimento Internacional: 2005-2009", que levantou, recentemente, entre diversos órgãos do aparelho burocrático brasileiro, o tama- 
nho do investimento em cooperação feito pelo país. O estudo, publicado em parceria pelo Ipea e pela ABC, concluiu que, entre 2005 e 2009, o Brasil investiu "uma cifra próxima a $\mathrm{R} \$ 2,9$ bilhões, em valores correntes" (Ipea, $A B C$, 2010, p. 19). Trata-se, entretanto, de uma primeira iniciativa, que, como os próprios autores reconhecem, ainda enfrenta desafios metodológicos merecedores de maior atenção por parte dos estudiosos da política externa brasileira. 


\section{A Ajuda Externa Brasileira 2005-2010}

Após a crise econômica de 2008, o Brasil passou a ser um interlocutor privilegiado das iniciativas econômicas globais de contenção de seus efeitos, principalmente por meio do G20, grupo criado, a princípio, sem poderes de deliberação, mas que ganhou força com a necessidade de reconhecer o peso de economias emergentes na economia mundial. Aliado a isso, uma combinação de regulamentação bancária conservadora, acertadas iniciativas governamentais e grande demanda externa (particularmente aquela proveniente do mercado de commodities chinês) garantiu um bom desempenho da economia brasileira em uma época de depressão econômica na maioria das economias centrais. O Brasil fincou mais profundamente suas raízes de potência no solo da economia mundial.

A esses fatores conjunturais se soma uma orientação deliberada do Estado brasileiro no sentido de ampliar sua presença internacional por meio de iniciativas de cooperação técnica. A revista "The Economist" identifica o Brasil como um dos maiores "provedores de ajuda" para países pobres, investindo, em 2010, um valor de aproximadamente 4 bilhões de reais em iniciativas que se estendem de empréstimos do BNDES à cooperação técnica por meio da Embrapa e ao apoio militar no Haiti. Nesta frente de atuação internacional, observa-se 
a preferência dada a acordos de cooperação sul-sul, ou seja, a cooperação com países em desenvolvimento.

A literatura identifica o início do governo Lula como um ponto de inflexão nas iniciativas de cooperação internacional encetadas pelo Brasil. Alden e Vieira (2005) observam que a partir de 2003 houve um esforço concertado no sentido de "cortejar" Estados da África, do Leste Asiático e, particularmente, a China, em contraste com uma perspectiva americanista com raízes nos anos 1960 e que teria dado o tom da política externa brasileira, em maior ou menor intensidade, até os governos de Fernando Henrique Cardoso.

Temos, assim, que a chegada do Partido dos Trabalhadores ao poder representou, segundo os autores um realinhamento da política externa do país, mas não constituiu um rompimento (p. 322) Lima e Hirst (2006), por sua vez, identificam, na evolução das ideias que definiram a conduta exterior brasileira a partir de meados do século $X X$, duas abordagens distintas competindo por espaço e influência nos escalões mais altos do Itamaraty: o primeiro, chamado de "busca de credibilidade", teria prevalecido nos governos de Fernando Henrique Cardoso e priorizaria uma linha de ação orientada pela percepção externa sobre o Brasil (p. 24). O país não teria, segundo os defensores desta abordagem, condições de fazer valer seus interesses por meio do uso exclusivo da força e dependeria, como consequência, do fortalecimento de instituições in- 
ternacionais nas quais faria valer seu poder de influência. Como corolário, a agenda internacional brasileira teria pouca autonomia interna e se esforçaria por se enquadrar em recomendações internacionais de atuação e regulamentação. Contrapor-se-iam a esses formuladores os proponentes da política externa com ênfase na autonomia, com um esforço de projeção explicitamente autóctone. Segundo as autoras, esta visão teria prevalecido, ainda que não completamente, no governo Lula, e seria a responsável pelo aumento dos investimentos brasileiros em esforços de cooperação sul-sul, dos quais seriam exemplos mais notáveis a iniciativa do IBSA e o comando das forças de pacificação da ONU no Haiti.

Pecequilo (2008) ecoa esta visão ao identificar uma mudança de foco da política externa brasileira a partir do governo Lula, com a manutenção do "Eixo Vertical" da política externa, ou seja, as relações estabelecidas com os países desenvolvidos, e o concomitante fortalecimento do "Eixo Horizontal", que é constituído pelas relações com países não-desenvolvidos. A autora aponta que a percepção oficial brasileira é a de que a recente mudança no eixo privilegiado das relações exteriores já produziu resultados positivos, de cuja evidência seria o desempenho da economia brasileira durante a crise de 2008. A autora cita o Ministro Celso Amorim: “Pegue um economista como o Albert Fishlow (da Columbia University). Em entrevista recente ele disse que o desenvolvimento 
dessas relações Sul-Sul é uma das razões pelas quais o Brasil encontra-se menos vulnerável aos problemas na economia americana" (p. 147).

Lima (2005), valorizando a questão da identidade na inserção internacional, relembra o status de "system-affecting state" que tinham países como Brasil, Índia e México na década de 1970. Segundo a autora, o Brasil vem tentando se posicionar no cenário internacional como um país em desenvolvimento sem perder a condição de país capaz de provocar mudanças significativas na esfera internacional (p. 3). Ainda que a existência de um centro de formação e socialização de diplomatas provoque alguma estabilidade na condução da política externa brasileira (p. 7), a autora identifica, em consonância com o restante da literatura, uma mudança de inclinação na política externa brasileira a partir do governo Lula, partindo da estratégia de "credibilidade" vigente no governo Fernando Henrique Cardoso para a estratégia de "autonomia": "a principal diferença entre os dois governos é de perspectiva, da visão internacional de cada um deles" (p. 12). Tal diferença, no entanto, significa um afastamento da identidade de emergente, associada à estratégia de "credibilidade" e uma aproximação da identidade de "system-affecting state", associada à estratégia de “autonomia" (p. 13)

Em uma perspectiva histórica mais ampla, Cervo (1994) identifica na ação diplomática brasileira dos anos 1930 aos anos 1990 uma atuação que se orienta 
"invariavelmente para a promoção do desenvolvimento nacional". Escrevendo antes da eleição do governo Lula e, portanto, em um contexto no qual o fluxo de cooperação internacional no país era mais centrípeto do que centrífugo, Cervo considera que o conceito de cooperação internacional no Brasil foi articulado em torno de três eixos básicos: o do significado político, que, com a pretensão de sintetizar a política externa brasileira na palavra "cooperação", pretendia sublinhar o viés não-bélico do país na arena internacional; o dos objetivos econômicos, entre eles o de fortalecer a política de substituição de exportações nos anos 1960 e o de aumentar a capacidade técnico-científica do país por meio de acordos com países industrializados; e, por fim, o do modus faciendi, que, nas palavras do autor, constituía "uma cooperação desideologizada, até mesmo despolitizada, que explorava oportunidades com realismo, que criava alternativas diante de obstáculos" (p.6).

Observa-se, assim, que a literatura identifica no conjunto de iniciativas brasileiras de cooperação internacional um instrumento que não só atende a interesses táticos para a obtenção de resultados específicos, mas que se subordina também a uma percepção estratégica da forma de inserção de longo prazo do país no cenário internacional. Podemos estender essa ideia para dizer que a cooperação internacional constitui parte do arsenal brasileiro de aplicação de seu soft power, definido por Joseph Nye (2004) como o exercício da influên- 
cia sobre os demais atores pela atração, em oposição à coerção. $\mathrm{O}$ fato de o governo Lula ser percebido como realizador de transição entre "potência regional discreta" para uma "potência de liderança cooperativa" [kooperativen Führungsmacht] (Gratius, 2004) não pode ser desvinculado de uma estratégia de inserção internacional que envolve a) um fluxo cada vez maior de doação de cooperação em função de um fluxo decrescente de recebimento de cooperação e b) um envolvimento cada vez maior com países não-desenvolvidos e em desenvolvimento em prejuízo de países desenvolvidos.

\subsection{Tipos de Projetos}

A Agência Brasileira de Cooperação foi criada, em setembro de 1987, com o fim de atender à necessidade de coordenar os esforços de cooperação no âmbito do Estado Brasileiro, servindo-se de recursos orçamentários dirigidos e da infraestrutura institucional necessária para operar a articulação entre os diferentes temas de cooperação. A agência é dividida em sete coordenações que abrangem desde infra-estrutura até temas relacionados à área social 


\begin{tabular}{|c|c|c|c|c|c|c|}
\hline & 2005 & 2006 & 2007 & 2008 & 2009 & Total \\
\hline $\begin{array}{c}\text { Ajuda } \\
\text { humanitária }\end{array}$ & 1,4 & 6,5 & 35,7 & 31,1 & 87,0 & 162,0 \\
\hline $\begin{array}{l}\text { Bolsas de estudos } \\
\text { para estrangeiros }\end{array}$ & 70,9 & 67,2 & 63,4 & 74,0 & 44,4 & 320,1 \\
\hline $\begin{array}{l}\text { Cooperação } \\
\text { Técnica Científica } \\
\text { e Tecnológica }\end{array}$ & 35,1 & 39,0 & 40,0 & 61,5 & 97,7 & 273,5 \\
\hline $\begin{array}{l}\text { Contribuições } \\
\text { para Organismos } \\
\text { Internacionais }\end{array}$ & 378,3 & 607,0 & 501,2 & 479,1 & 495,1 & $2.460,9$ \\
\hline Total & 485,8 & 719,9 & 640,5 & 645,9 & 724,4 & $3.216,7$ \\
\hline
\end{tabular}

Iglesias (2010) identifica esta instituição como "o ponto focal de toda a cooperação técnica brasileira" (p. 130) e chama a atenção para o fato de que ela, diferentemente de instituições semelhantes financiadas por países desenvolvidos, possui um caráter duplo: se encarrega tanto de acordos de cooperação recebida (de outros países ou de órgãos multilaterais, de que se ocupam primordialmente a Comissão Geral de Cooperação Técnica Recebida Bilateral e a Comissão Geral de Cooperação Técnica Recebida Multilateral) quanto de cooperação doada (a países em desenvolvimento, finalidade principal da Comissão Geral de Cooperação Técnica entre Países em Desenvolvimento). O autor destaca a crescente importância que o Estado brasileiro tem dado às iniciativas de cooperação sul-sul: “Outra ressalva importante é a de que a ABC está passando, desde o início de 2007, por uma reformulação interna, a qual tem 
por objetivo justamente fortalecer a área de CTPD [Cooperação Técnica para o Desenvolvimento], que será tomada em devida conta especialmente na análise dos problemas e das potencialidades da CTPD brasileira." (p. 131). De igual relevância para a análise do papel da cooperação sul-sul no contexto mais amplo da política externa brasileira é a existência de uma coordenadoria especialmente destinada às relações com países em desenvolvimento.

Sob a perspectiva do fortalecimento da Agência Brasileira de Cooperação, vale notar que Iglesias destoa da percepção expressada na maioria dos estudos sobre a política externa brasileira, qual seja, a de que a posse de Lula a partir de 2003 representou um movimento sensível no sentido de fortalecer a atuação do Estado brasileiro nessa área. O autor identifica entre 1995 e 2005 “dois momentos bastante diversos: o do crescimento e expansão a agência (1995 a 2001) e o de seu desafio institucional (2002 a 2005)" (p.131). O primeiro seria marcado pelo crescimento do volume de acordos assinados (tanto no que diz respeito à cooperação dada quanto no que diz respeito à cooperação recebida) e pela concentração de tarefas e atribuições antes fragmentadas em diferentes setores governamentais. O segundo, por sua vez, antes de se caracterizar pelo aumento do número de acordos ou pela mudança na direção dos fluxos de cooperação, se marcaria, ainda segundo o autor, pela consolidação institucional e pela superação de dificuldades jurídicas relacionadas à sua atuação. Deste 
modo, quatorze anos depois de sua fundação, a agência começaria a reagir de modo mais intensivo contra obstáculos acumulados ao longo do tempo, impulsionada, entre outros motivos, por questionamentos de órgãos oficiais de fiscalização orçamentária (p. 134). Ademais, a agência passa, nesse segundo momento, a investir em recursos de infra-estrutura próprios, já que tradicionalmente ocupava as instalações de representações do Ministério de Relações Exteriores em outros países.

\subsection{Organização burocrática}

Loose Interministerial Coordination

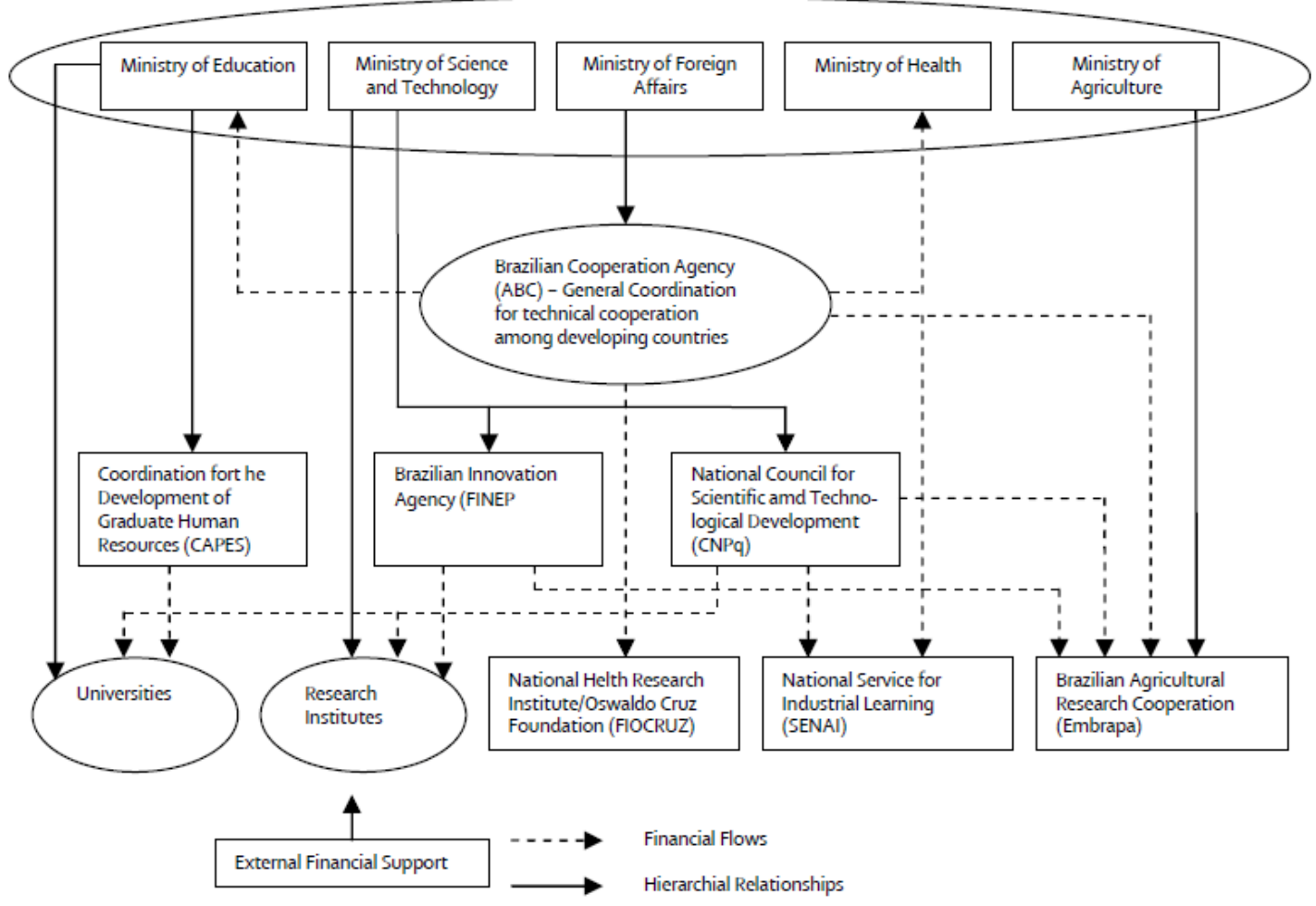


A crescente importância que o governo brasileiro vem dando ao relacionamento com países em desenvolvimento é exemplificada por Lopes (2008): enquanto entre 1995 e 2001 apenas 25\% das viagens presidenciais tinham esses países como destino, entre 2003 e março de 2006 esse número já tinha subido para 53,12\% (p. 120). Lopes nos alerta que esse aumento se deu de forma mais gradual do que a transição de lideranças políticas no período faria parecer, lembrando que, já no segundo mandato do presidente Fernando Henrique Cardoso, a proporção de viagens a países desenvolvidos começava a cair, principalmente devido a constrangimentos impostos na conjuntura internacional ("em especial a reação estadunidense aos ataques terroristas de setembro de 2001", p. 118). 


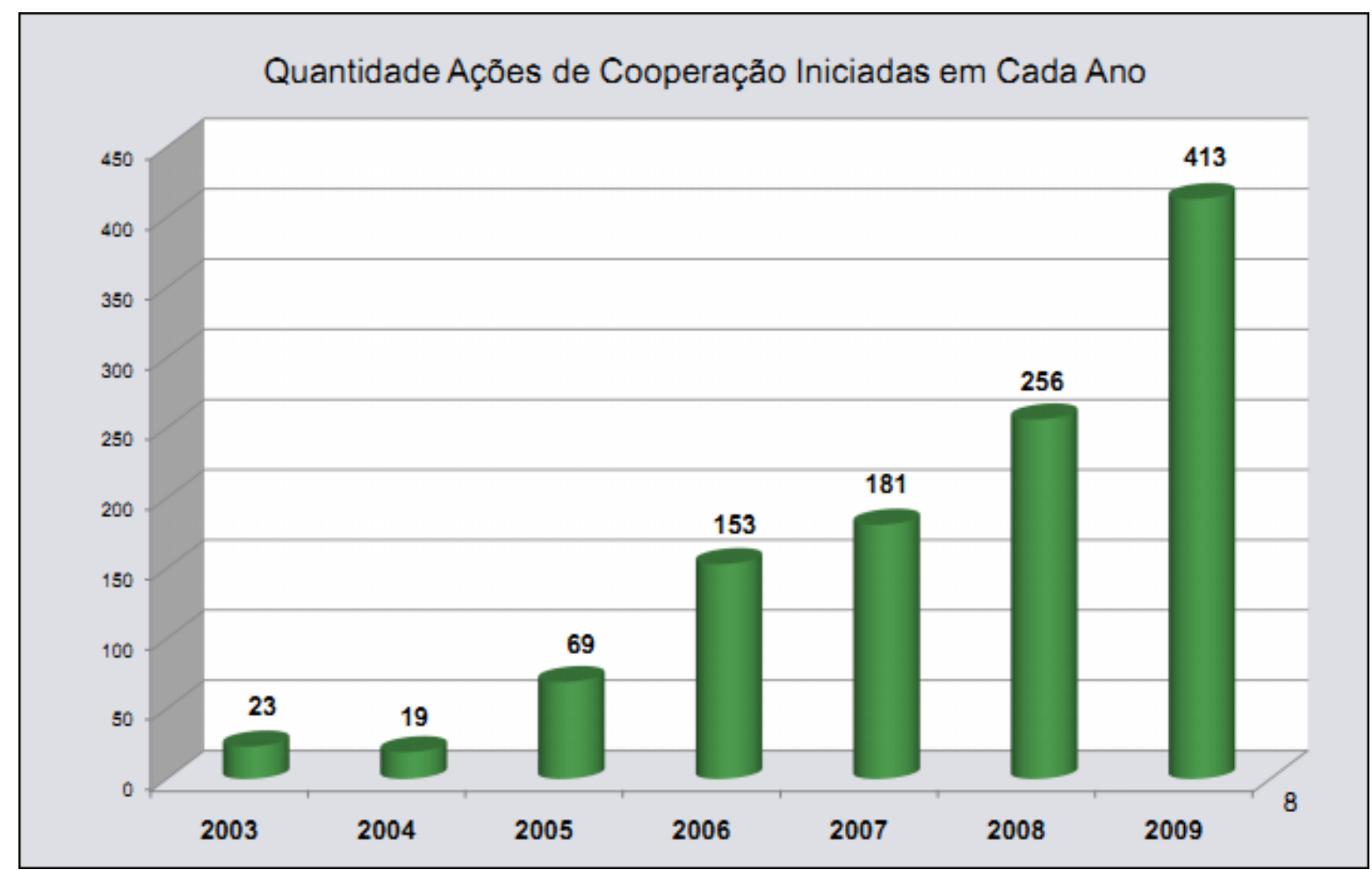

Ademais, sendo o Brasil membro da Organização das Nações Unidas, seu compromisso em fomentar o desenvolvimento por meio de cooperação com países em desenvolvimento é reforçado pelos Objetivos do Milênio. Entre as metas estabelecidas pelo plano de ação do programa e a serem cumpridas até 2015, está a destinação de 0,7\% do PIB dos países desenvolvidos para a Assistência Oficial ao Desenvolvimento. Ainda que não esteja entre o grupo de países que devem corresponder a essa meta, e apesar dos crescentes aportes em cooperação internacional, o país investe $0,02 \%$ de seu PIB em projetos dessa natureza (Ipea, ABC, 2010, p. 19) e demonstra preocupação pela perspectiva de que ela possa ser descumprida (Ipea, 2010a, p. 155). 


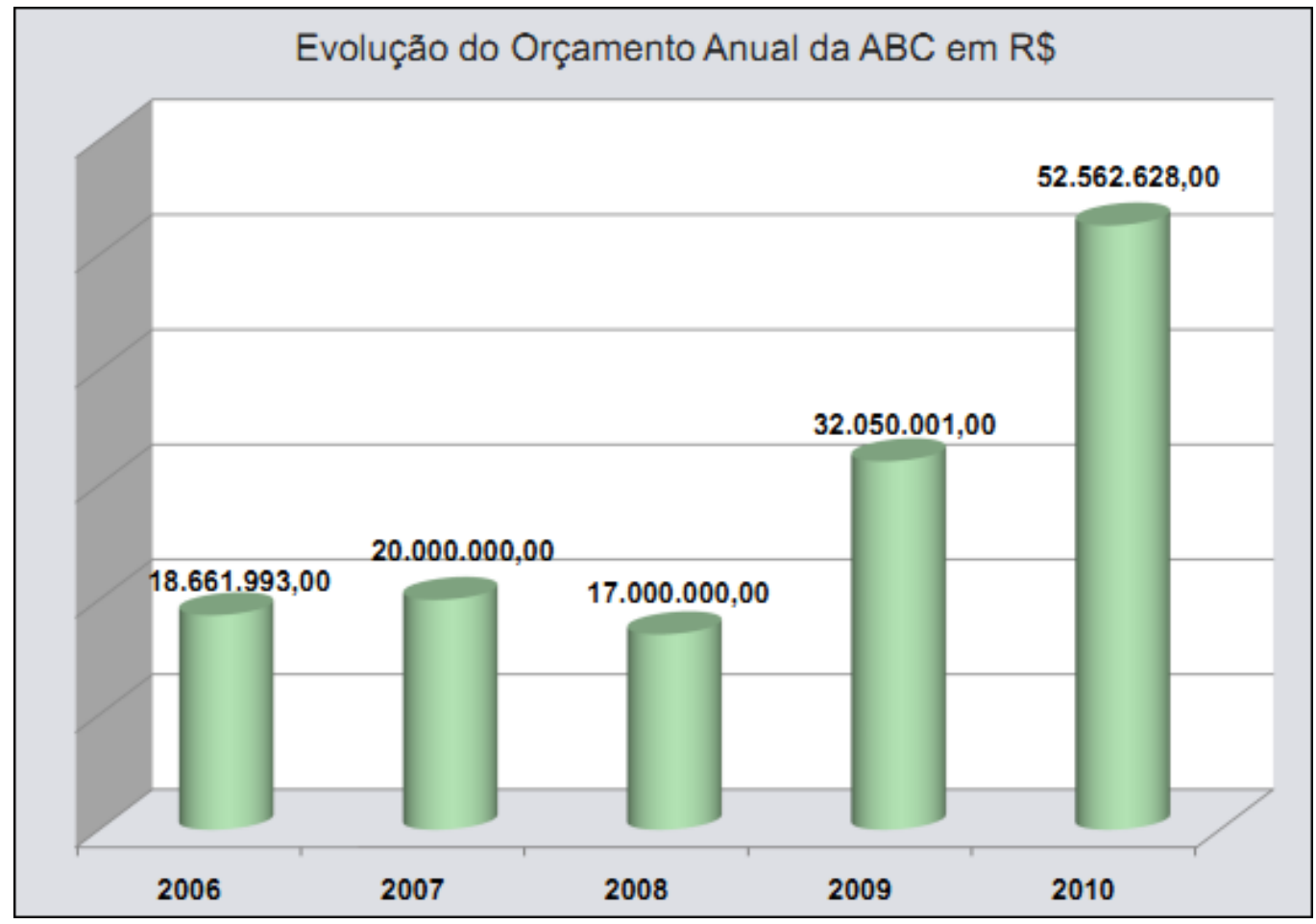

Temos, assim, que, para além de ter recebido cada vez maior atenção por parte do governo brasileiro, a Agência Brasileira de Cooperação ocupa uma posição privilegiada na articulação dos planos do país de inserção internacional no futuro. A percepção externa do Brasil como uma nação pacífica, de tradição não-intervencionista, revela-se um ativo crescentemente explorado não só pelos formuladores da política externa nacional, mas também almejado por países desenvolvidos que, por meio de parcerias de cooperação trilateral, têm interesse em se associar com o Brasil em projetos de desenvolvimento internacional. Outro indicador do reconhecimento por parte do governo federal da importância da Agência Brasileira de Cooperação para os objetivos de médio e longo prazos da política externa brasileira é o investimento no relatório “Co- 
operação para o Desenvolvimento Internacional: 2005-2009", que levantou, recentemente, entre diversos órgãos do aparelho burocrático brasileiro, o tamanho do investimento em cooperação feito pelo país. O estudo, publicado em parceria pelo Ipea e pela ABC, concluiu que, entre 2005 e 2009, o Brasil investiu "uma cifra próxima a R \$2,9 bilhões, em valores correntes" (Ipea, ABC, 2010, p. 19). Trata-se, entretanto, de uma primeira iniciativa, que, como os próprios autores reconhecem, ainda enfrenta desafios metodológicos merecedores de maior atenção por parte dos estudiosos da política externa brasileira. 


\section{Conclusão}

A literatura identifica o início do governo Lula como um ponto de inflexão nas iniciativas de cooperação internacional encetadas pelo Brasil. Alden e Vieira (2005) observam que a partir de 2003 houve um esforço concertado no sentido de "cortejar" Estados da África, do Leste Asiático e, particularmente, a China, em contraste com uma perspectiva americanista com raízes nos anos 1960 e que teria dado o tom da política externa brasileira, em maior ou menor intensidade, até os governos de Fernando Henrique Cardoso.

Após a crise econômica de 2008, o Brasil passou a ser um interlocutor privilegiado das iniciativas econômicas globais de contenção de seus efeitos, principalmente por meio do G20, grupo criado, a princípio, sem poderes de deliberação, mas que ganhou força com a necessidade de reconhecer o peso de economias emergentes na economia mundial. Aliado a isso, uma combinação de regulamentação bancária conservadora, acertadas iniciativas governamentais e grande demanda externa (particularmente aquela proveniente do mercado de commodities chinês) garantiu um bom desempenho da economia brasileira em uma época de depressão econômica na maioria das economias centrais. O Brasil fincou mais profundamente suas raízes de potência no solo da economia mundial. 
A esses fatores conjunturais se soma uma orientação deliberada do Estado brasileiro no sentido de ampliar sua presença internacional por meio de iniciativas de cooperação técnica. A revista "The Economist" identifica o Brasil como um dos maiores "provedores de ajuda" para países pobres, investindo, em 2010, um valor de aproximadamente 4 bilhões de reais em iniciativas que se estendem de empréstimos do BNDES à cooperação técnica por meio da Embrapa e ao apoio militar no Haiti. Nesta frente de atuação internacional, observa-se a preferência dada a acordos de cooperação sul-sul, ou seja, a cooperação com países em desenvolvimento.

Temos, assim, que a chegada do Partido dos Trabalhadores ao poder representou, segundo os autores um realinhamento da política externa do país, mas não constituiu um rompimento (p. 322) Lima e Hirst (2006), por sua vez, identificam, na evolução das ideias que definiram a conduta exterior brasileira a partir de meados do século XX, duas abordagens distintas competindo por espaço e influência nos escalões mais altos do Itamaraty: o primeiro, chamado de "busca de credibilidade", teria prevalecido nos governos de Fernando Henrique Cardoso e priorizaria uma linha de ação orientada pela percepção externa sobre o Brasil (p. 24). O país não teria, segundo os defensores desta abordagem, condições de fazer valer seus interesses por meio do uso exclusivo da força e dependeria, como consequência, do fortalecimento de instituições in- 
ternacionais nas quais faria valer seu poder de influência. Como corolário, a agenda internacional brasileira teria pouca autonomia interna e se esforçaria por se enquadrar em recomendações internacionais de atuação e regulamentação. Contrapor-se-iam a esses formuladores os proponentes da política externa com ênfase na autonomia, com um esforço de projeção explicitamente autóctone. Segundo as autoras, esta visão teria prevalecido, ainda que não completamente, no governo Lula, e seria a responsável pelo aumento dos investimentos brasileiros em esforços de cooperação sul-sul, dos quais seriam exemplos mais notáveis a iniciativa do IBSA e o comando das forças de pacificação da ONU no Haiti.

Este trabalho defendeu que a ajuda externa brasileira tem relação com emerge nos últimos anos com relação com o fluxo do comércio brasileiro com os países recipeindários, para além de crescer de acordo com as ambições de liderança regional do país e de atender ao objetivo de aproximar o país dos estados da Comunidade de Países de Língua Portuguesa.

Pecequilo (2008) ecoa esta visão ao identificar uma mudança de foco da política externa brasileira a partir do governo Lula, com a manutenção do "Eixo Vertical" da política externa, ou seja, as relações estabelecidas com os países desenvolvidos, e o concomitante fortalecimento do "Eixo Horizontal", que é constituído pelas relações com países não-desenvolvidos. A autora aponta que 
a percepção oficial brasileira é a de que a recente mudança no eixo privilegiado das relações exteriores já produziu resultados positivos, de cuja evidência seria o desempenho da economia brasileira durante a crise de 2008. A autora cita o Ministro Celso Amorim: “Pegue um economista como o Albert Fishlow (da Columbia University). Em entrevista recente ele disse que o desenvolvimento dessas relações Sul-Sul é uma das razões pelas quais o Brasil encontra-se menos vulnerável aos problemas na economia americana" (p. 147). Lima (2005), valorizando a questão da identidade na inserção internacional, relembra o status de "system-affecting state" que tinham países como Brasil, Índia e México na década de 1970. Segundo a autora, o Brasil vem tentando se posicionar no cenário internacional como um país em desenvolvimento sem perder a condição de país capaz de provocar mudanças significativas na esfera internacional (p. 3). Ainda que a existência de um centro de formação e socialização de diplomatas provoque alguma estabilidade na condução da política externa brasileira (p. 7), a autora identifica, em consonância com o restante da literatura, uma mudança de inclinação na política externa brasileira a partir do governo Lula, partindo da estratégia de "credibilidade" vigente no governo Fernando Henrique Cardoso para a estratégia de "autonomia": "a principal diferença entre os dois governos é de perspectiva, da visão internacional de cada um deles"' (p. 12). Tal diferença, no entanto, significa um afastamento da identidade de emergente, 
associada à estratégia de "credibilidade" e uma aproximação da identidade de "system-affecting state", associada à estratégia de "autonomia" (p. 13)

Em uma perspectiva histórica mais ampla, Cervo (1994) identifica na ação diplomática brasileira dos anos 1930 aos anos 1990 uma atuação que se orienta “invariavelmente para a promoção do desenvolvimento nacional". Escrevendo antes da eleição do governo Lula e, portanto, em um contexto no qual o fluxo de cooperação internacional no país era mais centrípeto do que centrífugo, Cervo considera que o conceito de cooperação internacional no Brasil foi articulado em torno de três eixos básicos: o do significado político, que, com a pretensão de sintetizar a política externa brasileira na palavra "cooperação", pretendia sublinhar o viés não-bélico do país na arena internacional; o dos objetivos econômicos, entre eles o de fortalecer a política de substituição de exportações nos anos 1960 e o de aumentar a capacidade técnico-científica do país por meio de acordos com países industrializados; e, por fim, o do modus faciendi, que, nas palavras do autor, constituía "uma cooperação desideologizada, até mesmo despolitizada, que explorava oportunidades com realismo, que criava alternativas diante de obstáculos" (p.6).

Observa-se, assim, que a literatura identifica no conjunto de iniciativas brasileiras de cooperação internacional um instrumento que não só atende a interesses táticos para a obtenção de resultados específicos, mas que se subor- 
dina também a uma percepção estratégica da forma de inserção de longo prazo do país no cenário internacional. Podemos estender essa ideia para dizer que a cooperação internacional constitui parte do arsenal brasileiro de aplicação de seu soft power, definido por Joseph Nye (2004) como o exercício da influência sobre os demais atores pela atração, em oposição à coerção. $\mathrm{O}$ fato de o governo Lula ser percebido como realizador de transição entre "potência regional discreta" para uma "potência de liderança cooperativa" [kooperativen Führungsmacht] (Gratius, 2004) não pode ser desvinculado de uma estratégia de inserção internacional que envolve a) um fluxo cada vez maior de doação de cooperação em função de um fluxo decrescente de recebimento de cooperação e b) um envolvimento cada vez maior com países não-desenvolvidos e em desenvolvimento em prejuízo de países desenvolvidos.

A Agência Brasileira de Cooperação foi criada, em setembro de 1987, com o fim de atender à necessidade de coordenar os esforços de cooperação no âmbito do Estado Brasileiro, servindo-se de recursos orçamentários dirigidos e da infraestrutura institucional necessária para operar a articulação entre os diferentes temas de cooperação. A agência é dividida em sete coordenações que abrangem desde infra-estrutura até temas relacionados à área social

Iglesias (2010) identifica esta instituição como "o ponto focal de toda a cooperação técnica brasileira" (p. 130) e chama a atenção para o fato de que ela, 
diferentemente de instituições semelhantes financiadas por países desenvolvidos, possui um caráter duplo: se encarrega tanto de acordos de cooperação recebida (de outros países ou de órgãos multilaterais, de que se ocupam primordialmente a Comissão Geral de Cooperação Técnica Recebida Bilateral e a Comissão Geral de Cooperação Técnica Recebida Multilateral) quanto de cooperação doada (a países em desenvolvimento, finalidade principal da Comissão Geral de Cooperação Técnica entre Países em Desenvolvimento). O autor destaca a crescente importância que o Estado brasileiro tem dado às iniciativas de cooperação sul-sul: "Outra ressalva importante é a de que a ABC está passando, desde o início de 2007, por uma reformulação interna, a qual tem por objetivo justamente fortalecer a área de CTPD [Cooperação Técnica para o Desenvolvimento], que será tomada em devida conta especialmente na análise dos problemas e das potencialidades da CTPD brasileira." (p. 131). De igual relevância para a análise do papel da cooperação sul-sul no contexto mais amplo da política externa brasileira é a existência de uma coordenadoria especialmente destinada às relações com países em desenvolvimento.

Sob a perspectiva do fortalecimento da Agência Brasileira de Cooperação, vale notar que Iglesias destoa da percepção expressada na maioria dos estudos sobre a política externa brasileira, qual seja, a de que a posse de Lula a partir de 2003 representou um movimento sensível no sentido de fortalecer a atua- 
ção do Estado brasileiro nessa área. O autor identifica entre 1995 e 2005 “dois momentos bastante diversos: o do crescimento e expansão a agência (1995 a 2001) e o de seu desafio institucional (2002 a 2005)" (p.131). O primeiro seria marcado pelo crescimento do volume de acordos assinados (tanto no que diz respeito à cooperação dada quanto no que diz respeito à cooperação recebida) e pela concentração de tarefas e atribuições antes fragmentadas em diferentes setores governamentais. O segundo, por sua vez, antes de se caracterizar pelo aumento do número de acordos ou pela mudança na direção dos fluxos de cooperação, se marcaria, ainda segundo o autor, pela consolidação institucional e pela superação de dificuldades jurídicas relacionadas à sua atuação. Deste modo, quatorze anos depois de sua fundação, a agência começaria a reagir de modo mais intensivo contra obstáculos acumulados ao longo do tempo, impulsionada, entre outros motivos, por questionamentos de órgãos oficiais de fiscalização orçamentária (p. 134). Ademais, a agência passa, nesse segundo momento, a investir em recursos de infra-estrutura próprios, já que tradicionalmente ocupava as instalações de representações do Ministério de Relações Exteriores em outros países.

A crescente importância que o governo brasileiro vem dando ao relacionamento com países em desenvolvimento é exemplificada por Lopes (2008): enquanto entre 1995 e 2001 apenas 25\% das viagens presidenciais tinham es- 
ses países como destino, entre 2003 e março de 2006 esse número já tinha subido para 53,12\% (p. 120). Lopes nos alerta que esse aumento se deu de forma mais gradual do que a transição de lideranças políticas no período faria parecer, lembrando que, já no segundo mandato do presidente Fernando Henrique Cardoso, a proporção de viagens a países desenvolvidos começava a cair, principalmente devido a constrangimentos impostos na conjuntura internacional ("em especial a reação estadunidense aos ataques terroristas de setembro de 2001", p. 118).

Ademais, sendo o Brasil membro da Organização das Nações Unidas, seu compromisso em fomentar o desenvolvimento por meio de cooperação com países em desenvolvimento é reforçado pelos Objetivos do Milênio. Entre as metas estabelecidas pelo plano de ação do programa e a serem cumpridas até 2015, está a destinação de 0,7\% do PIB dos países desenvolvidos para a Assistência Oficial ao Desenvolvimento. Ainda que não esteja entre o grupo de países que devem corresponder a essa meta, e apesar dos crescentes aportes em cooperação internacional, o país investe $0,02 \%$ de seu PIB em projetos dessa natureza (Ipea, ABC, 2010, p. 19) e demonstra preocupação pela perspectiva de que ela possa ser descumprida (Ipea, 2010a, p. 155).

Temos, assim, que, para além de ter recebido cada vez maior atenção por parte do governo brasileiro, a Agência Brasileira de Cooperação ocupa uma 
posição privilegiada na articulação dos planos do país de inserção internacional no futuro. A percepção externa do Brasil como uma nação pacífica, de tradição não-intervencionista, revela-se um ativo crescentemente explorado não só pelos formuladores da política externa nacional, mas também almejado por países desenvolvidos que, por meio de parcerias de cooperação trilateral, têm interesse em se associar com o Brasil em projetos de desenvolvimento internacional. Outro indicador do reconhecimento por parte do governo federal da importância da Agência Brasileira de Cooperação para os objetivos de médio e longo prazos da política externa brasileira é o investimento no relatório "Cooperação para o Desenvolvimento Internacional: 2005-2009", que levantou, recentemente, entre diversos órgãos do aparelho burocrático brasileiro, o tamanho do investimento em cooperação feito pelo país. O estudo, publicado em parceria pelo Ipea e pela ABC, concluiu que, entre 2005 e 2009, o Brasil investiu "uma cifra próxima a R\$2,9 bilhões, em valores correntes" (Ipea, ABC, 2010, p. 19). Trata-se, entretanto, de uma primeira iniciativa, que, como os próprios autores reconhecem, ainda enfrenta desafios metodológicos merecedores de maior atenção por parte dos estudiosos da política externa brasileira. 


\section{Referências}

Asch, S. E. (1956). Studies of independence and conformity: I. a minority of one against a unanimous majority. Psychological Monographs: General and Applied, 70(9):1-70. 24

Axelrod, R. M. (2006). The evolution of cooperation. Basic Books, New York. 17

Beck, N. and Katz, J. (1995). What to do (and not to do) with time-series crosssection data. American Political Science Review, page 634-647. 13

Bonacich, P., Shure, G. H., Kahan, J. P., and Meeker, R. J. (1976). Cooperation and group size in the n-person prisoners' dilemma. Journal of Conflict Resolution, 20(4):687-706. 26

Bornstein, G. and Yaniv, I. (1998). Individual and group behavior in the ultimatum game: Are groups more rational players? Experimental Economics, 1(1):101-108. 23, 25

Bräutigam, D. (2012). Chinese development aid in africa: What, where, why, and how much? 13

Camerer, C. F. (2003). Behavioral Game Theory: Experiments in Strategic Interaction. Princeton University Press. 23

Davis, J. H. (1992). Some compelling intuitions about group consensus decisi- 
ons, theoretical and empirical research, and interpersonal aggregation phenomena: selected examples 1950-1990. Organizational Behavior and Human Decision Processes, 52(1):3-38. 24

Ferraz, C. and Finan, F. (2009). Motivating politicians: The impacts of monetary incentives on quality and performance. 29

Grieco, J., Powell, R., and Snidal, D. (1993). The relative-gains problem for international cooperation. The American Political Science Review, 87(3):727-743. ArticleType: research-article / Full publication date: Sep., 1993 / Copyright (C) 1993 American Political Science Association. 28

Jensen, N. M. (2012). Politics and Foreign Direct Investment. University of Michigan Press. 12

Kahneman, D. (2013). Thinking, fast and slow. Farrar, Straus and Giroux, New York. 23

Kahneman, D. and Tversky, A. (1979). Prospect theory: An analysis of decision under risk. Econometrica: Journal of the Econometric Society, page 263-291. 23

Kerr, N. L., MacCoun, R. J., and Kramer, G. P. (1996). Bias in judgment: Comparing individuals and groups. Psychological review, 103(4):687. 24

Knack, S. (2004). Does foreign aid promote democracy? International Studies Quarterly, 48(1):251-266. 14 
Kocher, M. G. and Sutter, M. (2005). The decision maker matters: Individual versus group behaviour in experimental beauty-contest games. The Economic Journal, 115(500):200-223. ArticleType: research-article / Full publication date: Jan., 2005 / Copyright (c) 2005 Royal Economic Society. 24, 25

Kono, D. Y. and Montinola, G. (2009). Does foreign aid support autocrats, democrats, or both? Journal of Politics, 71(2):704-718. 12

Kugler, T., Bornstein, G., Kocher, M. G., and Sutter, M. (2007). Trust between individuals and groups: Groups are less trusting than individuals but just as trustworthy. Journal of Economic Psychology, 28(6):646-657. 25

Mesquita, B. B. d. and Smith, A. (2007). Foreign aid and policy concessions. Journal of Conflict Resolution, 51(2):251-284. 13

Mesquita, B. B. d. and Smith, A. (2009). Political survival and endogenous institutional change. Comparative Political Studies, 42(2):167-197. 12

Milner, H. and Tingley, D. (2010). The political economy of US foreign aid: American legislators and the domestic politics of aid. Economics $\mathcal{E}$ Politics, 22(2):200-232. 12

Morrow, J. D. (1994). Game theory for political scientists. Princeton University Press, Princeton, N.J. 29

Nagel, R. (1995). Unraveling in guessing games: An experimental study. The 
American Economic Review, 85(5):1313-1326. 25

Osborne, M. J. (2004). An introduction to game theory. Oxford University Press, New York. 16

Pehnelt, G. (2007). The political economy of china's aid policy in africa. Jena Economic Research Paper, (2007-051). 32

Prather, L. (2011). Individual determinants of foreign aid support: Do individuals think like states? 28

Salois, M. J. Regional changes in the distribution of foreign aid: An entropy approach. Physica A: Statistical Mechanics and its Applications. 27

Sartori, A. E. (2003). An estimator for some binary-outcome selection models without exclusion restrictions. Political Analysis, 11(2):111-138. 27

Schopler, J. and Insko, C. A. (1992). The discontinuity effect in interpersonal and intergroup relations: Generality and mediation. European review of social psychology, 3(1):121-151. 24

Shapiro, I., Smith, R. M., and Masoud, T. E. (2004). Problems and Methods in the Study of Politics. Cambridge University Press. 28

Signorino, C. S. (1999). Strategic interaction and the statistical analysis of international conflict. American Political Science Review, page 279-297. 26 
Simplice, A. (2012). The political economy of development assistance: Peril to government quality dynamics in africa. 26

Vreeland, J. (2011). Foreign aid and global governance: Buying bretton woods - the swiss-bloc case. The Review of International Organizations, page 1-23. 26 